\title{
EL DERECHO A LA IGUALDAD ANTE LA LEY, NO DISCRIMINACIÓN Y ACCIONES POSITIVAS*
}

\section{Humberto Nogueira Alcalá $\AA^{* *}$}

RESUMEN: En el presente artículo se analiza el derecho a la igualdad ante la ley en su evolución doctrinal y de derecho positivo en el ordenamiento constitucional como asimismo en las líneas jurisprudenciales de la Corte Suprema y el Tribunal Constitucional cbileno, sin perjuicio de tener en consideración información comparativa jurisprudencial de otros tribunales constitucionales y de la Corte Interamericana de Derechos Humanos. Asimismo el artículo desarrolla el principio de no discriminación y el fundamento jurídico de las acciones positivas.

PALABRAS ClAVE: Igualdad ante la ley e igualdad en la ley - Principio de proporcionalidad - Principio de no discriminación - Igualdad de oportunidades y acciones positivas.

\section{THE RIGHT OF EQUALITY BEFORE THE LAW, NON-DISCRIMINATION AND POSITIVE ACTIONS}

ABSTRACT: This article analyzes the right of equality before the law in its doctrinal evolution and of positive law in the constitutional ordinance as well as the jurisprudence framework of the Supreme Court and the Chilean Constitutional Court, notwithstanding bearing into consideration comparative legal information of other constitutional courts and of the International Court of Human Rights. The article develops the principle of non-discrimination and the juridical basis of positive actions as well.

KEY WORDS: Equality before the law - Principle of proportionality - Principle of non-discrimination - Equality of opportunities and positive actions.

El presente artículo forma parte del Proyecto Enlace FONDECYT, de la Universidad de Talca E000122 de 2006.

* El autor es Director del Centro de Estudios Constitucionales de Chile (www.cecoch.cl), Profesor Titular de Derecho Constitucional y Director del Magíster en Derecho Constitucional de la Universidad de Talca, Campus Santiago (CHILE). Presidente de la Asociación Chilena de Derecho Constitucional (www.constitucional.cl) y Vicepresidente del Instituto Iberoamericano de Derecho Procesal Constitucional. Correo electrónico: nogueira@utalca.cl Fecha de recepción: 21 de agosto de 2006.

Fecha de aprobación: 20 de noviembre de 2006. 
SUMARIO: 1. Introducción. 2. La igualdad ante la Ley. 2.1. Un cambio de paradigma: de la igualdad mediante la ley al derecho de igualdad por la ley sometida a la Constitución y los derechos humanos. 2.2. El derecho a la igualdad como probibición de discriminación o de diferencias arbitrarias. 2.2.1. La consideración del principio de proporcionalidad como parte del análisis de la infracción de la igualdad ante la ley. 2.3. La carga de la prueba sobre la razonabilidad de la norma o el carácter de relevante de las diferencias. 3. Las modalidades de la discriminación o la diferenciación arbitraria. 3.1. La discriminación de género y de grupos históricamente postergados. 4. La tutela positiva de la igualdad o igualdad promocional: la igualdad de oportunidades y las acciones positivas, afirmativas o de discriminación inversa. Consideraciones finales.

\section{INTRODUCCIÓN}

El principio de igualdad parte en el nivel de conciencia jurídica actual de la humanidad de la igual dignidad de toda persona humana, lo cual es sostenido tanto por las declaraciones y tratados internacionales en materia de derechos humanos, como por el texto de las constituciones contemporáneas posteriores a la Segunda Guerra Mundial, constituyendo la igual dignidad de toda persona el fundamento de todos los derechos fundamentales, del orden constitucional, como asimismo constituye un principio de ius cogens en el ámbito del derecho internacional.

El Pacto Internacional de Derechos Civiles y Políticos de Naciones Unidas en su preámbulo, parte "Considerando que, conforme a los principios enunciados por la Carta de Naciones Unidas, la libertad, la justicia y la paz en el mundo tienen por base el reconocimiento de la dignidad inherente a todos los miembros de la familia bumana y de sus derechos iguales e inalienables", como asimismo, reconoce "que estos derechos se derivan de la dignidad inherente a la persona bumana".

Por su parte, la Convención Americana de Derechos Humanos o Pacto de San José de Costa Rica, precisa en su preámbulo que, "los derechos esenciales del hombre no nacen del becho de ser nacional de determinado Estado, sino que tienen como fundamento los atributos de la persona bumana, razón por la cual justifican una protección internacional, de naturaleza convencional coadyuvante o complementaria de la que ofrece el derecho interno de los Estados Americanos".

El reconocimiento y aseguramiento de la igual dignidad de todas las personas es independiente de la edad, capacidad intelectual o estado de conciencia. Esta igual dignidad se predica respecto de todas y cada una de las personas o seres humanos y no de las personas jurídicas.

Una noción de la igual dignidad de los seres humanos es aquella que se predica como un valor espiritual y moral inherente a toda persona, que 
se manifiesta en la autodeterminación consciente y responsable de su propia vida, llevando consigo la pretensión del respeto por parte de los demás y la idea que las personas son siempre sujetos y nunca instrumentos o medios para el desarrollo de otros fines.

En virtud de esta igual dignidad común a todos los seres humanos se fundamentan los derechos humanos o derechos fundamentales de la persona humana, que igualmente pertenecen a cada uno y a todos los seres humanos por tener la dignidad de seres humanos, de personas. Ello nos permite ya una primera afirmación con consecuencias jurídicas prácticas en el ámbito constitucional, que es el de que siempre la dignidad de la persona está por sobre todo otro principio o valor, por tanto, ninguna norma jurídica ni aun un derecho de la persona puede ir en contra de la dignidad humana, ya que esta constituye su propio fundamento y el mínimo de humanidad respecto del cual no está permitida realizar diferenciaciones.

Dicha dimensión está expresa y claramente recogida en el constitucionalismo histórico chileno y en nuestra Constitución vigente, especialmente en las bases de la institucionalidad, artículo $1^{\circ}$, el cual determina que "Las personas nacen libres e iguales en dignidad y derechos".

En cuanto principio, constituye el enunciado de un contenido sustantivo objetivo que, en cuanto componente axiológico del orden constitucional, vincula de modo general e irradia todo el ordenamiento jurídico ${ }^{1}$.

La segunda faceta del principio de igualdad consiste en el derecho a la igualdad ante la ley, aspecto sobre el cual concentraremos el análisis de este trabajo, considerando su sentido y alcance jurídico, como asimismo sus implicancias con el principio de no discriminación y las acciones positivas.

La igualdad en cuanto derecho fundamental reconoce la titularidad de toda persona sobre el bien jurídico igualdad, que es oponible a todo destinatario, que implica el derecho a no ser discriminado por razones de carácter subjetivo u otras que resulten jurídicamente relevantes, con el consiguiente mandato correlativo respecto de los órganos o autoridades estatales y los particulares de prohibición de discriminación.

El principio y derecho a la igualdad se proyectan siempre en dos niveles diferentes: la igualdad ante la ley y la igualdad en la ley.

La igualdad ante la ley se refiere a la eficacia de los mandatos de la igualdad en la aplicación en el ámbito administrativo, en el ámbito jurisdiccional y en la relación entre particulares. 
La igualdad en la ley se refiere a la igualdad como derecho fundamental, a su eficacia vinculante frente al derecho, frente al legislador ${ }^{2}$.

\section{LA IGUALDAD ANTE LA LEY}

La igualdad ante la ley constituye una segunda perspectiva que adopta la igualdad en al ámbito constitucional de los estados como en el ámbito del derecho internacional de los derechos humanos.

En el ámbito interno de los Estados, una primera dimensión de la igualdad ante la ley tiene sus antecedentes en la declaración de la independencia de los Estados Unidos en 1776 y en la Revolución Francesa de 1789 , siendo asumida luego por el constitucionalismo clásico y contemporáneo, por el cual se reconoce la igual naturaleza y atributos esenciales a todos los seres humanos.

Esta dimensión, en perspectiva histórica, lleva a eliminar la esclavitud como expresión del desconocimiento de la dignidad humana y la igualdad esencial de las personas. En el ordenamiento jurídico chileno ello se reflejó tempranamente, en 1811 se declaró la libertad de vientres y la Carta Fundamental de 1823 abolió la esclavitud ${ }^{3}$ y en homenaje a ello, los textos constitucionales posteriores, incluido el actualmente vigente han mantenido dicho principio. Así, el artículo $19 \mathrm{~N}^{\circ} 2$ de la Constitución chilena vigente asegura a todas las personas:

"2. la igualdad ante la ley. En Chile no bay persona ni grupo privilegiados. En Chile no hay esclavos y el que pise su territorio queda libre. Hombres y mujeres son iguales ante la ley".

Esta igualdad básica de naturaleza de todos los seres humanos, asumida por los ordenamientos jurídicos, exige eliminar las discriminaciones en el ámbito sociológico, prohibiendo toda distinción basada en aspectos subjetivos de las personas por motivos de raza, color, sexo, idioma, religión, opiniones políticas o de cualquier índole, origen nacional o social, posición económica, nacimiento o cualquier otra condición social.

La introducción de la frase "Hombres y mujeres son iguales ante la ley" en la reforma constitucional de $1999^{4}$, más que introducir un elemento sustantivo nuevo, constituyó el cumplimiento de tratados internacionales que obligaban formalmente a establecer específicamente el principio en el texto constitucional, como asimismo, por razones de lenguaje constitucional, con el objeto de establecer un lenguaje equitativo y no discriminatorio en materia de género, lo que llevó también a sustituir las

Sobre la materia ver ANDRADE GEYWITZ, Carlos. Elementos de Derecho Constitucional Chileno. Ed. Jurídica de Chile, Santiago, 1963. pp. 172 y siguientes.

Molina Guaita, Hernán. Derecho Constitucional. LexisNexis, Santiago, 2006. p. 261.

Ley de reforma constitucional $\mathrm{N}^{\circ} 19.611$ de 16 de junio de 1999. 
expresiones "hombres" por "personas" en el artículo $1^{\circ}$, inciso $1^{\circ}$ de la Constitución, en la misma reforma.

Además de su regulación en los ordenamientos constitucionales y legales de los Estados, tal derecho queda estampado en la Declaración Universal de Derechos Humanos y en el Pacto Internacional de Derechos Civiles y Políticos de Naciones Unidas, la igualdad ante la ley se positiva en un derecho humano y se constituye en un principio imperativo de derecho internacional o principio de ius cogens a la no discriminación.

El Pacto Internacional de Derechos Civiles y Políticos determinará en su artículo 26, que "Todas las personas son iguales ante la ley y tienen derecho sin discriminación a igual protección de la ley. A este respecto, la ley probibirá toda discriminación y garantizará a todas las personas protección igual $y$ efectiva contra cualquier discriminación por motivos de raza, color, sexo, idioma, religión, opiniones políticas o de cualquier índole, origen nacional o social, posición económica, nacimiento o cualquier otra condición social".

A su vez, la Convención Americana de Derechos Humanos, en forma más escueta, en su artículo 24, determina que "todas las personas son iguales ante la ley. En consecuencia, tienen derecho, sin discriminación, a igual protección de la ley". La misma convención en su artículo $1^{\circ}$ ya había precisado que "1. Los estados partes en esta Convención se comprometen a respetar los derechos y libertades reconocidos en ella y garantizar su libre y pleno ejercicio a toda persona que esté sujeta a su jurisdicción, sin discriminación alguna por motivos de raza, color, sexo, idioma, religión, opiniones políticas o de cualquier otra indole, origen nacional o social, posición económica, nacimiento o cualquier otra condición social".

Es necesario precisar la existencia de un núcleo duro de la igualdad establecido en el derecho internacional de los derechos humanos (Pacto Internacional de Derechos Civiles y Políticos, artículo 24\% ; Convención Americana de Derechos Humanos, artículo $1^{\circ}$ ) como son el de que la diferenciación no puede justificarse en razón de raza, sexo, origen nacional o familiar, lengua, religión, opinión filosófica o política, siendo las diferencias realizadas por el legislador basadas en tales situaciones, en principio, ilegítimas.

Existe hoy un común denominador o criterio compartido en el ámbito de las jurisdicciones constitucionales y en las cortes internacionales de derechos humanos que determina que cuando la diferenciación es hecha en base al sexo, la raza, la creencias religiosas, las opiniones políticas, u otros criterios prohibidos expresamente por los tratados internacionales o por la Constitución, la ley se presume inconstitucional mientras la autoridad no demuestre lo contrario.

Por tanto, toda diferencia basada en cualquier dimensión subjetiva es sospechosa de inconstitucionalidad, debiendo ser sometida a un riguroso análisis de razonabilidad y proporcionalidad, el cual en última instancia, debe ser determinado por parte de la jurisdicción constitucional, o la corte internacional de derechos humanos competente, en su caso. 
La jurisprudencia de nuestros tribunales nacionales avala esta perspectiva, a manera ejemplar puede señalarse una Sentencia de la Corte de Apelaciones de Valparaíso, la cual precisa:

"Que, por lo que toca a la igualdad ante la ley, es útil dejar en claro que ella requiere una aplicación a todos los habitantes de la república de manera uniforme y sin discriminaciones injustas o arbitrarias en cuanto a su interpretación, valoración y alcance de sus efectos jurídicos e impide establecer estatutos legales diferentes, atendiendo a razones de raza, condición social, estirpe, fortuna, religión, ideología u otros atributos estrictamente particulares"s.

La prohibición de diferenciar respecto de aspectos subjetivos de la persona constituye un límite a la función legislativa, ejecutiva y judicial, como asimismo, a la autonomía privada.

El artículo $19 \mathrm{~N}^{\circ} 2$ de la Constitución en armonía con el artículo $5^{\circ}$ inciso segundo y el contenido de los derechos asegurados por el Pacto Internacional de Derechos Civiles y Políticos y la Convención Americana de Derechos Humanos, exige un test de control de constitucionalidad riguroso del principio y derecho de igualdad, cuando el factor diferencial es de carácter subjetivo como la raza, la religión, el nacimiento, la ideología, entre otros aspectos. En tales casos la carga de la prueba corresponde a quienes sostengan la legitimidad de la diferenciación en base a tales factores $^{6}$. En este ámbito no opera el principio de presunción de constitucionalidad de las normas legales.

2.1. Un cambio de paradigma: de la igualdad mediante la ley al derecho de igualdad por la ley sometida a la Constitución y los derechos humanos

En una perspectiva evolutiva histórica, el pensamiento liberal que impregnaba el constitucionalismo del siglo XIX y primera parte del siglo $\mathrm{XX}$, conectaba el principio de generalidad de la ley y el principio de igualdad, prohibiendo toda forma de diferenciación, generando como consecuencia jurídica la igualdad de todos en el ejercicio de los derechos individuales. Inicialmente la igualdad ante la ley implicaba solamente igualdad en el contenido de la ley en cuanto norma general, abstracta y atemporal, además de dotar de igual capacidad jurídica a todas las personas sin distinción alguna. Tal perspectiva buscaba eliminar los privilegios y arbi-

Sentencia de la Corte de Apelaciones de Valparaíso de 16 de abril de 1998, considerando 11; confirmada por Sentencia de la Corte suprema de Justicia de 14 de mayo de 1998. XCV Revista de Derecho y Jurisprudencia, 2p. Sección 5, p. 91.

6 SUAY RINCÓN, José. El principio de igualdad en la justicia constitucional. Instituto de Estudios de la Administración Local, Madrid, 1985. p. 168. 
trariedades generados por los regímenes monárquicos y la estructura social estamental.

La ley era el único tertium comparationes jurídicamente relevante. Ello imponía a la ley misma, algunas condicionantes como son su generalidad, su abstracción y su duración indefinida. "La ley es igual para todos porque es general y abstracta, pero el legislador al establecerla, no tiene otros límites, que derivan de esta estructura necesaria, respetada la cual puede dotar de relevancia jurídica a cualquier diferencia ficticia que la realidad ofrezca. El principio de igualdad exige la aplicación de la ley, pero en modo alguno se puede hacer derivar de él una protección jurídica frente al legislador" ${ }^{\text {" }}$. La igualdad es entendida durante el siglo XIX y principios del siglo XX como mera realización de la legalidad, sin referencia a dimensiones valóricas superiores.

Los órganos judiciales eran aplicadores de la ley (actuaban segundum legem) y, en consecuencia, el único derecho de las personas es el derecho a la legalidad, el estar igualmente sometidos a la ley.

Esta dimensión histórica decimonónica de la igualdad ante la ley constituye la facultad de toda persona para defenderse frente a normas estatales que diferencien en forma arbitraria o irrazonablemente su regulación jurídica frente a otros que se encuentran en las mismas circunstancias.

Esta perspectiva fue insuficiente e ineficaz, ya que omitía toda consideración sociológica como son las circunstancias económicas, sociales, culturales y educativas que condicionaban la vida real de las personas, excluyendo elementos básicos para la comprensión y tratamiento de la realidad social, reproduciendo o acentuando las graves disparidades en el ámbito socioeconómico ${ }^{8}$.

Frente a esta realidad se desarrolla la crítica democrática de fines del siglo XIX y de la primera mitad del siglo XX, que va a otorgar al Estado un mayor protagonismo en la vida social, tratando de corregir la graves desigualdades sociales, dentro de su tarea y fin que es el bien común, reconociéndose la posibilidad de dictar normas destinadas a ciertos grupos sociales que se encuentran en una situación determinada y específica diferente de la de otros grupos, como asimismo, se asume la injusticia de tratar de igual forma a quienes se encuentran ante distintas realidades sociales relevantes, lo que trae consigo la destrucción del dogma de la universalidad de la ley y el desarrollo del principio de igualdad de oportunidades, como asimismo, la tarea promotora del Estado para disminuir

\footnotetext{
7 Rubio Llorente, Francisco. La igualdad en la jurisprudencia del Tribunal Constitucional. Revista Española de Derecho Constitucional, $N^{\circ} 31$, Madrid, España, 1991. p. 20.

8 GARcfa PELAYO, Manuel. Las transformaciones del Estado contemporáneo. Alianza Editorial, Madrid, 1977. pág. 23. Ver asimismo, GÓmez SÁnCHEZ, Yolanda. 2003. Derechos y libertades. Ed. Sanz y Torres, Madrid, p. 134.
} 
las desigualdades materiales y generar las condiciones sociales que posibiliten la igualdad de oportunidades.

Ello implica un cambio de paradigma, se pasa de la concepción del Estado formal y liberal de derecho a la concepción del Estado material y social de Derecho, como asimismo, se pasa del Estado legal al Estado constitucional. En esta nueva concepción la igualdad constituye el núcleo básico de la justicia, del derecho justo.

Es así el constitucionalismo posterior a la Segunda Guerra Mundial el que incorporará la vertiente de la igualdad en el contenido de las leyes, como asimismo el complemento de la igualdad formal con la igualdad de oportunidades, complementando el primero como asimismo, transformándolo parcialmente.

Ello posibilita el paso de la igualdad mediante la ley a la garantía de la igualdad por la ley y en la ley dentro del marco constitucional, el legislador queda vinculado por el derecho a la igualdad en el tratamiento jurídico que debe darle a las personas. El legislador no es más la medida de la igualdad, sino que el legislador está sometido al principio de la igualdad, a no establecer discriminación, a no establecer diferencias arbitrarias, ya que ello vulnera el derecho constitucional a la igualdad ante la ley. cional.

Así puede sostenerse que la igualdad tiene un carácter bistórico y rela-

El carácter histórico de la igualdad está dado por las distintas concepciones de la igualdad a través del tiempo, como hemos visto, la concepción de la igualdad del siglo XIX no es la misma del siglo XXI. A través del proceso histórico las concepciones de la igualdad cambian.

Asimismo, la igualdad tiene un carácter relacional porque es en la relación entre las personas donde se manifiesta la igualdad y la desigualdad, en la medida que su contenido viene dado siempre respecto de relaciones jurídicas concretas, donde es necesario que actúe un determinado parámetro?

Así se señala que el derecho a la igualdad no tiene un carácter autónomo, sino relacional ya que opera para asegurar el goce efectivo del conjunto de derechos que el ordenamiento jurídico a partir de la Carta Fundamental reconoce y asegura a todas las personas.

El derecho a la igualdad ante la ley, en una perspectiva jurídica significa que, en todos los aspectos relevantes, las personas deben ser tratadas $y$ consideradas de igual manera a menos que haya una razón suficiente para no bacerlo.

SOSA SACIO, Juan Manuel. "El derecho-principio e igualdad en la Carta de 1993, con especial referencia a la jurisprudencia del Tribunal Constitucional", en Revista Peruana de Derecho Público, año $6 \mathrm{~N}^{\circ} 11$, julio-diciembre 2005, p. 166. 


\subsection{El derecho a la igualdad como prohibición de discriminación o de diferencias arbitrarias}

El derecho a la igualdad ante la ley y en la ley constituye un derecho subjetivo, ya que es una facultad o atributo inherente a toda persona a no ser objeto de discriminación, vale decir, de un trato basado en diferencias arbitrarias.

En el plano de la aplicación, la igualdad ante la ley obliga a que esta sea aplicada de modo igual a todos aquellos que se encuentran en la misma situación, sin que el operador pueda establecer diferencia alguna en razón de las personas, o de circunstancias que no sean precisamente las presentes en las normas" 10 .

Las diferencias que corresponden a otros ámbitos ajenos al núcleo duro (condiciones subjetivas de la igualdad) como son las condiciones objetivas, pueden ser regulados por el legislador, pero estas diferenciaciones de tratamiento de personas o grupos de personas deben estar justificadas racionalmente. La discriminación, la diferencia arbitraria, se encuentra en oposición a la justicia, siendo inconstitucional y contraria a los derechos humanos.

Así surge también en el derecho internacional de los derechos humanos el principio de no discriminación como uno de los derechos más básicos del ser humano, el cual ha sido elevado a la categoría de Ius Cogens, el que prohíbe toda diferenciación hecha sobre fundamentos no razonables, irrelevantes o desproporcionados.

En el plano interno de los Estados, los ordenamientos constitucionales aseguran también esta dimensión de la igualdad ante la ley. La Constitución chilena la contempla en el artículo $19 \mathrm{~N}^{\circ} 2$, inciso segundo, el cual asegura a todas las personas que:

"Ni la ley ni autoridad alguna podrán establecer diferencias arbitrarias".

Parte de la doctrina diferencia discriminación y diferencia arbitraria.

La discriminación sería un ataque o conducta desviada más profunda que la mera diferencia sin fundamento, sería una distinción manifiestamente contraria a la dignidad humana, fundada en un prejuicio negativo, por el cual se trata a los miembros de un grupo como seres diferentes $y$, eventualmente, inferiores, siendo el motivo de distinción odioso e inaceptable por la humillación que implica a quienes son marginados por la aplicación de dicha discriminación ${ }^{11}$. En esta perspectiva, las causas de discriminación son aquellas que tienen las personas independientemente

10 Ver Rubio Llorente, Francisco. Derechos Fundamentales y Principios Constitucionales. Ed. Ariel, Derecho, España, 1995. pp. 110-111.

il Bilbao Ubillos, Juan María y Rey Martínez, Fernando. "El principio constitucional de igualdad en la jurisprudencia constitucional española", en CARBONELL, Miguel (compilador). El principio de igualdad constitucional. Comisión Nacional de Derechos humanos, México. 2003. p. 111. 
de su voluntad tales como su origen, sexo, raza, idioma, condición social, como aquellas asumidas voluntariamente por las personas, que constituyen manifestaciones esenciales de su personalidad, las cuales llegan a constituir derechos fundamentales, como son las discriminaciones producidas con motivo de concepciones religiosas, ideológicas, filiación política, opción sexual, entre otras ${ }^{12}$.

El derecho a no ser objeto de discriminación ha sido aplicado en diferentes casos por los tribunales de justicia respecto de actos tanto de autoridades como de sujetos privados. Un ejemplo expresivo ha sido un fallo de la Corte de Apelaciones de Santiago, confirmado por la Corte Suprema de Justicia, en que una señora de origen coreano le fue impedida su entrada a la institución Piscina Mund, en la que se brindaban servicios al público de baños turcos y de cajón, en temporada invernal. La persona afectada presentó una acción constitucional de protección ante la Corte de Apelaciones de Santiago. Dicha Corte, haciendo una correcta aplicación del bloque constitucional de derechos fundamentales respecto del derecho a la igualdad ante la ley, asegurados por vía del artículo $19 \mathrm{~N}^{\circ} 2$ de la Constitución y por los tratados de derechos humanos ratificados y vigentes, determinó:

"Que el hecho de impedir a una persona o grupo de personas poder entrar en un lugar público o de atención al público en general, sea gratuito o pagado, basadas en circunstancias de raza, sexo, idioma, religión o cualquiera otra circunstancia étnica, social o cultural implica un trato desigual y discriminatorio que contraviene los principios que boy imperan en las sociedades modernas relativos a derechos humanos, contenidos en la Carta de Naciones Unidas, Pacto Internacional de Derechos Civiles y políticos, y Convención Americana sobre Derechos Humanos que son leyes de la república en conformidad a lo dispuesto en el artículo $5^{\circ}$ inciso $2^{\circ}$ de nuestra Carta Fundamental.

Que por mucho que se haya invocado, para impedir el acceso a una persona de una determinada nacionalidad al centro de salud de que se trata, el hecho que las costumbres alimenticias de las personas de esa nacionalidad hacen que tenga mal olor, o de grupos de personas de esa nacionalidad hayan perturbado con sus bábitos a la clientela de ese negocio, no es menos cierto que, además de significar la conducta de los responsables del centro de salud 8...). una discriminación racial, resulta además una actuación injusta y atentatoria a la dignidad bumana. Injusta por cuanto por aquello en que incurrieron otros de la misma nacionalidad o grupo étnico de la denunciante, se le bizo a esta acreedora de una sanción moral; atentatoria a la dignidad humana pues la referida discriminación y los razonamientos para justificarla

12 SORIANO TORRES, Marta. "La igualdad no como uniformidad de tratamiento jurídico sino como prohibición de discriminación”. En Anales de la Facultad de Derecho N ${ }^{\circ} 19$. Universidad de La Laguna, diciembre de 2002, p. 260. 
implican además una injuria en menoscabo de una persona $y$ de todos los componentes de un grupo racial"13.

La discriminación es así la diferencia arbitraria, es la desigualdad de tratamiento de las personas carente de justificación objetiva y razonable, como asimismo, es el tratamiento igual de personas que se encuentran en situaciones en que hay diferencias jurídicas relevantes, que obligarían a un tratamiento diferenciado.

El principio de no discriminación puede formularse de la siguiente forma: "a menos que exista una razón reconocida como relevante y suficiente, según algún criterio identificable $y$ aceptado, ninguna persona puede ser preferida a otra"14.

En la misma perspectiva lo ha asumido la jurisprudencia de la Corte Suprema de Justicia chilena, estableciendo que por "discriminación arbitraria ha de entenderse toda diferenciación o distinción realizada por el legislador o cualquier autoridad pública que aparezca como contraria a la ética elemental o a un proceso normal de análisis intelectual; en otros términos, que no tenga justificación racional o razonable, lo que equivale a decir que el legislador no puede, por ejemplo, dictar una ley que imponga distintos requisitos $u$ obligaciones a personas distintas en iguales circunstancias" 15 .

Así, cuando nuestro artículo $19 \mathrm{~N}^{\circ}$ 2, en su inciso final, precisa que "ni la ley ni autoridad alguna podrán establecer diferencias arbitrarias", debemos interpretar que ninguna autoridad, consideradas todas aquellas establecidas por la Constitución y el ordenamiento jurídico, toda persona que ejerza poder público dentro del ámbito legislativo, de gobierno de administración o jurisdiccional tiene prohibido establecer normas y acciones discriminatorias. Asimismo, la igualdad no es solo frente a la ley, sino que es frente al derecho: la Constitución, la ley, los reglamentos, los autoacordados y cualquier otra norma jurídica ${ }^{16}$. No debe olvidarse que los derechos constituyen límites a la soberanía, como expresa imperativamente el artículo $5^{\circ}$ inciso $2^{\circ}$ de la Constitución.

El legislador debe tratar igual a las personas que se encuentran en situaciones e hipótesis jurídicas iguales y debe tratar diferenciadamente a quienes se encuentran en situaciones o hipótesis jurídicas diferentes.

La igualdad consiste así en una relación, la que debe ser justa, ajena a toda arbitrariedad o diferenciación sin justificación racional y razonable.

13 Sentencia de la Corte de Apelaciones de Santiago de 7 de abril de 1993, Rol N ${ }^{\circ}$ 486-93, considerandos 1 y 2, confirmada por Sentencia de la Corte Suprema de Justicia de 7 de septiembre de 1993, Rol N 621.

14 RABOSSI, Eduardo. Derechos Humanos: El principio de igualdad y la discriminación. Revista Centro de Estudios Constitucionales, $N^{\circ} 7$, Madrid, España, 1990. p. 179.

15 Sentencia de la Corte Suprema de Justicia de 24 de mayo de 1991 , considerando $4^{\circ}$. En Revista de Derecho y Jurisprudencia LXXXVIII, $2^{\circ}$, pág. 182.

16 Molina Guarta, Hernán. Derecho Constitucional, Ed. LexisNexis, Santiago, 2006. p. 261. 
Así surge el principio o regla en materia de igualdad ante la ley de que las situaciones iguales deben ser tratadas iguales y que las situaciones desiguales deben ser tratadas desigualmente, siendo inconstitucional tratar igualmente a bipótesis jurídicas diferentes, como asimismo, es inconstitucional tratar diferentemente a quienes se encuentran en una misma hipótesis jurídica.

Estos principios habilitan al legislador para establecer preceptos legales referentes a diferentes hipótesis jurídicas que afectan a grupos humanos diversos atendiendo las particularidades de cada situación concreta, siempre que se basen en aspectos relevantes y razonables.

Es así como el Tribunal Constitucional chileno en sentencia del 8 de abril de 1985, Rol No 28 establece que "la igualdad ante la ley consiste en que las normas jurídicas deben ser igual para todas las personas que se encuentren en las mismas circunstancias y que no deben concederse privilegios ni imponerse obligaciones a unos que no beneficien o graven a otros que se ballan en condiciones similares. No se trata, por consiguiente, de una igualdad absoluta sino que ba de aplicarse la ley en cada caso conforme a las diferencias constitutivas del mismo. La igualdad supone, por lo tanto, la distinción razonable entre quienes no se encuentran en la misma condición; por lo que ella no impide que la legislación contemple en forma distinta situaciones diferentes, siempre que la discriminación no sea arbitraria ni responda a un propósito de hostilidad contra determinada persona o grupo de personas, o importe indebido favor o privilegio personal o de grupo"17.

Por otra parte, el mismo criterio es sostenido por la Corte Suprema chilena, en sentencia del 15 de junio de 1988 donde establece, "la igualdad ante la ley es el sometimiento de todas las personas de similares condiciones a un mismo estatuto jurídico fundamental para el ejercicio de sus derechos y para el cumplimiento de sus deberes, sin que sea posible discriminar entre ellas, por lo que es natural que, en una serie de ámbitos, la ley pueda hacer diferencias entre grupos, siempre y cuando no sea una discriminación arbitraria, esto es, contraria a la ética elemental o que no tenga una justificación racional"18.

En otra sentencia, en que analiza la constitucionalidad de diversas disposiciones que modifican la LOC de Municipalidades, el Tribunal Constitucional chileno determinó: " $E l$ derecho a percibir una remuneración o sueldo está siempre ligado al ejercicio de un cargo; esto es lo normal y por consiguiente es lo que corresponde aplicar en la generalidad de las funciones públicas. Si todos están sometidos a esta norma básica, se quiebra esta igualdad

17 Blanc, N; Nogueira, H; Pfeffer, E; Verdugo, M. La Constitución chilena. Tomo I. Ed. Centro de Estudios y Asistencia Legislativa. Universidad Católica de Valparaíso, Chile, 1990. p. 97. En el mismo sentido, Sentencia del Tribunal Constitucional, de fecha 6 de diciembre de 1994, Rol $\mathrm{N}^{\circ} 203$, considerando $11^{\circ}$.

is Verdugo, Mario; Pfeffer, Emilio; Nogueira, Humberto. Derecho Constitucional. Tomo I. Editorial Jurídica de Chile. Santiago, Chile, 1994. p. 210, cita 30. 
cuando se dispone por una ley y en forma infundada que un funcionario, que no obstante no ejercer su cargo, por el solo becho de estar postulando a la posible renovación del mismo, tenga derecho a continuar percibiendo la remuneración correspondiente al cargo que no se encuentra ejerciendo. En el caso específico que propone el proyecto se infringe la garantía constitucional en comento, como quiera que sin que medie una causal razonablemente justa o idónea para obtener el referido privilegio, se da el caso de que unos mismos funcionarios que, estando en la misma situación, aparecen, sin embargo, en desigualdad de condiciones respecto de la exigencia de desempeñar el cargo para tener derecho a percibir sus remuneraciones"19.

A su vez, en el derecho comparado, el Tribunal Constitucional español en sentencia 49 de 1982, ha establecido que: "la igualdad a que el artículo 14 se refiere, que es la igualdad jurídica o ante la ley, no comporta necesariamente una igualdad económico y efectiva, significa que a los supuestos de bechos iguales han se serles aplicadas unas consecuencias juridicas que sean iguales también y que para introducir diferencias entre los supuestos de becho tiene que existir un suficiente justificación de tal diferencia que aparezca al mismo tiempo, como fundada y razonable de acuerdo con criterios y juicios de valor generalmente aceptados". "La regla general de igualdad ante la ley... contempla, en primer lugar la igualdad en el trato dado por la ley o igualdad en la ley y constituye desde este punto de vista un límite puesto al ejercicio del Poder Legislativo, pero es asimismo igualdad en la aplicación de la ley, lo que impone que un mismo órgano no puede modificar arbitrariamente el sentido de sus decisiones en casos sustancialmente iguales y que cuando el órgano en cuestión considere que debe apartarse de sus precedentes tiene que ofrecer para ello una fundamentación suficiente y razonable".

Una Sentencia de la Corte Constitucional de Colombia, caso "Empresa Singer", de noviembre 1995, estableció que "El becho de pertenecer a un sindicato no puede dar origen a la discriminación en materia de sueldos $y$ prestaciones sociales. No resulta justificado ni legitimado el trato diferenciado que se da a una $u$ otra clase de trabajadores. Es más, podría pensarse que el origen de la discriminación se centra en la pertenencia de algunos trabajadores al sindicato" 20 .

Tal como la jurisprudencia constitucional lo demuestra, es el juicio de razonabilidad dentro del cual deben ser entendido el principio de igualdad. No en vano ha señalado, por ejemplo el Tribunal Constitucional italiano, que el principio de igualdad es reconducible a esa exigencia de coherencia interna del ordenamiento jurídico que se presenta como un

19 Sentencia del Tribunal Constitucional chileno, Rol $N^{\circ} 145$, de fecha 26 de mayo de 1992, considerando $6^{\circ}$.

20 Venegas Castellanos, Alfonso. Teoría y Práctica de la acción de tutela. Editores AVC Colombia, 1996, p. 181. 
valor esencial para la cultura de la que él mismo es expresión (Sentencia 30 de diciembre de 1982; No 204, Foro It. 1982, I, 1981).

La razonabilidad implica que solo se autoriza la intervención en un derecho fundamental cuando hay un fundamento que lo autorice, la razonabilidad implica así prohibición de arbitrariedad.

En esta perspectiva, el Tribunal Constitucional peruano ha determinado que:

"Por virtud del principio de razonabilidad se exige que la medida restrictiva se justifique en la necesidad de preservar, proteger o promover un fin constitucionalmente valioso. Es la protección de fines constitucionalmente relevantes lo que, en efecto, justifica una intervención estatal en el seno de los derechos fundamentales. Desde esta perspectiva, la restricción de un derecho fundamental satisface el principio de razonabilidad cada vez que este persiga garantizar un fin legítimo $y$, además, de rango constitucional" 21 .

Así la igualdad ante la ley tutela a las personas frente a los eventuales privilegios, a los actos y normas discriminatorias o sin fundamento racional o justo, como asimismo, ante las eventuales irracionalidades del mismo ordenamiento jurídico.

En otra sentencia del Tribunal Constitucional español, la $n^{\circ} 144$ de 1988, se establece lo siguiente:

"El principio de igualdad que garantiza la Constitución opera en dos planos distintos. De una parte, frente al legislador o frente al poder reglamentario, impidiendo que uno u otro puedan configurar los supuestos de becho de la norma de modo tal que se dé trato distinto a personas que, desde todos los puntos de vista legítimamente adoptables se encuentren en la misma situación, o dicho de otro modo, impidiendo que se otorgue relevancia jurídica a circunstancias que, o bien no pueden ser tomadas nunca en consideración por probibirlo así expresamente la propia Constitución, o bien no guardan relación alguna con el sentido de la regulación que, al incluirlas, incurre en arbitrariedad y es por eso discriminatoria".

En la sentencia señalada a modo ejemplar se realiza solo un análisis de la arbitrariedad, en estos casos la igualdad se vulnera cuando no se encuentra una razón objetiva para establecer una regulación jurídica diferenciada, por lo cual dicha regulación jurídica debe ser considerada arbitraria. No existe así la posibilidad de introducir elementos o factores de diferenciación cuando este último carece de racionalidad, cuando no es necesario el factor diferencial para la protección del bien o bienes jurídicos que el legislador busca proteger.

Sin embargo, hay casos difíciles, en los cuales hay un mandato de trato igualitario a destinatarios cuyas situaciones presentan similitudes y diferencias, lo que lleve al trato igual a pesar de la diferencia, que se basa

21 Sentencia del Tribunal Constitucional peruano, Exp. $\mathrm{N}^{\circ}$ 045-2004-PI/TC, considerando 23. 
en el principio de prohibición de discriminación. Asimismo, también hay un mandato de trato diferenciado a destinatarios que se encuentran en posiciones en parte similar y en parte diferente o diversa, pero en cuyo caso las diferencias son más relevantes que las similitudes, lo que lleva al trato diferenciado a pesar de las similitudes, aquí nos encontramos con el deber de promoción del bien común (artículo 1 inciso 4 de la Constitución chilena) y de igualación de oportunidades o protección de los desfavorecidos como deber estatal (inciso final del artículo $1^{\circ}$ de la Constitución chilena). Siendo estos los casos que se generan problemas interpretativos, no los casos fáciles.

Los casos son difíciles porque la prohibición de discriminación y el deber de promoción de establecer una efectiva igualdad de oportunidades son conceptos jurídicamente indeterminados o vagos, ya que no existe claridad cuando un trato diferenciado de varios grupos se encuentra permitido, prohibido o es obligatorio desde una perspectiva constitucional, ni como deben ser reparadas las violaciones al principio de igualdad ${ }^{22}$. Corresponde al Tribunal Constitucional determinar dicho contenido, enjuiciando la constitucionalidad de leyes, normas y actos administrativos. Dicha determinación se realiza mediante la fundamentación y concreción de una norma adscrita ${ }^{23}$, que también pueden denominarse subreglas constitucionales. Ello no implica que el Tribunal Constitucional pueda generar discrecionalmente normas adscritas o subreglas constitucionales, ya que ellas solamente serán legítimas cuando resulten de una fundamentación correcta, basada en el texto de la Constitución y sus principios.

Durante mucho tiempo, las jurisdicciones constitucionales operaron con la aplicación del principio de no aceptar diferencias arbitrarias, posición que era liderada por el tribunal constitucional alemán, asumiendo la postura doctrinaria de Leibholz en la época de Weimar, que sostenía que el principio de igualdad se vulneraba cuando la disposición enjuiciada debía ser catalogada como arbitraria ${ }^{24}$.

Dicho criterio cambiará a inicios de la penúltima década del siglo $\mathrm{XX}$, incluyendo en el análisis el principio de proporcionalidad ${ }^{25}$.

Sobre la materia ver, GonZÁlez Berlfuss, M. Tribunal Constitucional y reparación de la discriminación normativa. Ed. Centro de Estudios Políticos y Constitucionales. Madrid, 2000.

23 Sobre la materia ver: BERNAL PUlido. El principio de proporcionalidad. Op. cit. I, III, 2.2. 24 BVerfGE 1, 14 (52).

25 BVerfGE 55, 72 (88). Ver asimismo, Bernal Pulido, Carlos. El derecho de los derechos. Ed. Universidad Externado de Colombia, Bogotá, 2005. pág. 261. 


\subsubsection{La consideración del principio de proporcionalidad como parte del análisis de la infracción de la igualdad ante la ley}

Sin embargo, el principio de igualdad no se reduce a la prohibición de tratos desiguales sin fundamento racional. La igualdad ante la ley tiene un carácter relativo y proporcional. En efecto, cuando se establece una diferenciación basada en grupos de personas o una diferenciación referidas a circunstancias que se traduce en tratamiento desigual de personas, se debe desarrollar un análisis atendiendo, además, al principio de proporcionalidad, ya que ese trato desigual puede comprometer otros derechos fundamentales o bienes constitucionales protegidos.

El principio de proporcionalidad no se encuentra previsto de una manera expresa en el texto constitucional chileno, este se deduce, está implícito en las reglas del Estado de derecho, siendo un principio inherente a este $^{26}$. Asimismo, el principio de proporcionalidad emerge, además de los principios elementales del Estado de derecho existentes en nuestro ordenamiento jurídico, del artículo $19 \mathrm{~N}^{\circ} 26$ de la Constitución chilena en cuanto garantía frente al legislador que puede afectar el contenido esencial de los derechos, formando parte de la dogmática de los derechos fundamentales, en que el Estado y sus órganos se encuentran vinculados por los derechos fundamentales.

Como señala Barnes, pese a la "moderna formulación técnico-jurídica, relativamente reciente, la noción de proporcionalidad aparece íntimamente relacionada con la idea de justicia material y, por consiguiente, ha estado presente, de un modo u otro, en la historia del pensamiento jurídico"27.

Serán las cortes internacionales de derechos humanos las primeras en utilizar el principio de proporcionalidad en materia de igualdad ante la ley, cuando el legislador regula aspectos vinculados con el derecho a la igualdad ante el ordenamiento jurídico.

Vale la pena en esta materia recordar, entre otras sentencias de la Corte Europea de Derechos Humanos, el "caso Alejandra Marckx", sentencia del 13 de junio de 1979 , en la cual se reclamaba de las diferencias de tratamiento en el Código Civil Belga ente hijos legítimos e ilegítimos, donde el Tribunal Europeo concluyó que si bien es legítimo apoyar a la familia tradicional no debe recurrirse con tal objetivo a medios que causen perjuicios a la familia natural. De tal manera que se consideró que dicha norma del Código Civil belga era contraria a la igualdad, por ser

\footnotetext{
26 BARNES, J. "Introducción al principio de proporcionalidad en el Derecho Comparado y comunitario", en Revista de Administración Pública Na 5, España, 1994. p. 500.

27 BARNES, J. "Introducción al principio de proporcionalidad", en Cuadernos de Derecho Público $N^{\circ}$ 5, España, 1998, p. 11.
} 
una medida desproporcionada y por haber otros medios más adecuados para reforzar la familia tradicional, considerándose ilegítimo limitar los derechos sucesorios de los hijos naturales, al no estar dicha medida justificada objetiva y razonablemente.

A su vez, la Corte Europea de Derechos Humanos, en el caso relativo a ciertos aspectos de las leyes en el uso del lenguaje en educación en Bélgica (Merite), sentencia del 23 de julio de 1988, estableció: "la igualdad de trato queda violada cuando la distinción carece de justificación objetiva y razonable. La existencia de una justificación semejante debe apreciarse en relación con la finalidad y los efectos de la medida examinada en atención a los principios que generalmente prevalecen en la sociedades democráticas. Una diferencia de trato en el ejercicio de un derecho consagrado por el convenio no solo debe perseguir una finalidad legitima: el art. 14 se ve también violado cuando resulta claramente que no existe una razonable relación de proporcionalidad entre los medios empleados y la finalidad perseguida. Al indagar si, en un caso determinado, ha habido o no distinción arbitraria, el Tribunal no puede ignorar los datos de hecho y de derecho que caractericen la vida de la sociedad en el Estado en el que, en calidad de parte contratante, responde la medida impugnada".

Por otra parte, la Corte Interamericana de Derechos Humanos, en 1984, a petición del gobierno de Costa Rica, desarrolló la Opinión Consultiva $\mathrm{N}^{\circ} 4$, referente a una posible norma constitucional en la cual se establecía que la mujer no costarricense que contrajera matrimonio con un costarricense obtendría en ciertas condiciones la nacionalidad del marido. La Corte Interamericana en dicha Opinión Consultiva $\mathrm{N}^{\circ} 4$ declaró dicha cláusula discriminatoria, teniendo como fundamentos, entre otros, los siguientes: "no babrá, pues discriminación si una distinción de tratamiento está orientada legítimamente, es decir, si no conduce a situaciones contrarias a la justicia, a la razón y a la naturaleza de las cosas. De ahí que no pueda afirmarse que exista discriminación en toda diferencia de tratamiento del Estado frente al individuo siempre que esa distinción parta de supuestos hechos sustancialmente diferentes y que expresan de modo proporcionando una fundada conexión entre esas diferencias y los objetivos de las normas, los cuales no pueden apartarse de la justicia de la razón, vale decir, no pueden perseguir fines arbitrarios, caprichosos, despóticos o que de alguna manera repugnen a la esencial unidad y dignidad de la naturaleza bumana. Si bien no puede desconocerse que la circunstancia de hecho pueda ser más o menos difícil de apreciar si se está o no en presencia de una situación como la descrita en el párrafo anterior, es también cierto que, partiendo de la base de la dignidad del ser humano, es posible apreciar circunstancias en que los imperativos del bien común puedan justificar una mayor o menor grado de distinción que no se aparten de las consideraciones precedentes. Se trata de valores que adquieren dimensiones concretas a la luz de la realidad en la que están 
llamados a materializarse y que dejan un cierto margen de apreciación para la expresión que deben asumir en cada caso".

El principio de proporcionalidad lo desarrolla la jurisprudencia del Tribunal Constitucional alemán, expandiéndose en la jurisprudencia de los tribunales constitucionales europeos y latinoamericanos. En efecto el Tribunal Constitucional alemán sostendrá que la eventual contravención del principio de igualdad a través de una ley implica un examen que de la simple prohibición de arbitrariedad alcanza hasta una estricta vinculación a la exigencia de proporcionalidad, se vulnera el principio y derecho a la igualdad "cuando un grupo de destinatarios de una norma es tratado de manera distinta, en comparación con otros destinatarios de la misma, a pesar de que entre los dos grupos no existan diferencias de tal tipo y de tal peso que puedan justificar el trato diferente ${ }^{28}$.

El principio de proporcionalidad en términos generales es conceptualizado como prohibición constitucional de medidas excesivas, el cual se descompone en tres subprincipios:

\section{a) Subprincipio de adecuación}

Este subprincipio exige que el legislador utilice medios idóneos que tiendan al objetivo legítimo y constitucional propuesto por la legislación, siendo coherente el medio con el fin. La idoneidad es la relación de causalidad de medio a fin, entre el medio adoptado a través de la intervención legislativa y el fin propuesto por el legislador. En el caso del análisis de una intervención en la prohibición de discriminación, el escrutinio consistirá en examinar si el tratamiento diferenciado establecido en el precepto legal por el legislador conduce a la obtención del fin constitucionalmente legítimo. En caso que no sea idóneo para logralo, el medio legislativo empleado será inconstitucional.

\section{b) Subprincipio de necesidad}

Este subprincipio exige al legislador utilizar aquel medio legislativo de entre los posibles que siendo necesario para el logro de la finalidad perseguida, afecte menos los derechos e intereses de las personas, lo que exige al legislador aplicar aquella medida legislativa más moderada que logre el propósito buscado teniendo la eficacia necesaria. La regla es la utilización del medio legislativo alternativo menos restrictivo de los derechos e igualmente eficaz para alcanzar el objetivo propuesto. Se trata de un escrutinio de una relación medio-medio, de una comparación entre

28 Sentencia Tribunal Constitucional Federal alemán, Primera Sala, BVerfGE 55 72(88), de fecha 7 de octubre de 1980 . 
medios. Se parte de la comparación entre medios idóneos, aquel que ha escogido el legislador y otros medios alternativos idóneos. El análisis sobre los medios alternativos se realiza en relación al objetivo del trato diferenciado. Si del análisis resulta que hay al menos un medio idóneo que no interviene en la prohibición de discriminación, o que, interviniendo en ella, tal intervención es de menor intensidad que la adoptada por el legislador, la ley será inconstitucional por infracción del principio de igualdad.

\section{c) Subprincipio de proporcionalidad en sentido estricto o de ponderación}

Este subprincipio exige al legislador ponderar en forma adecuada la intensidad del daño o lesión que la medida legislativa causa a los derechos e intereses de las personas, y el beneficio que la medida significa en relación al bien común. En el caso que nos interesa, el análisis del trato diferenciado, concite en la comparación entre el grado de realización u optimización del fin constitucional y el grado de intervención en la igualdad, lo que debe realizarse de acuerdo a una ponderación, la cual implica que cuanto mayor sea el gado de la no satisfacción o de la afectación de un principio, tanto mayor debe ser la satisfacción de otro. La ponderación en el caso de la igualdad supone la colisión entre el derecho igualdad el fin constitucional del trato diferenciado. Así cuanto mayor sea la intervención o afectación de la igualdad, tanto mayor debe ser el grado de realización u optimización del fin constitucional. Si esta relación se cumple la medida legislativa de intervención en la igualdad será constitucional, por el contrario, en el supuesto que la intensidad de la afectación de la igualdad sea mayor al grado de realización del fin constitucional, la intervención en la igualdad no estará justificada y será inconstitucional. El legislador debe evitar los medios legislativos que generen afectación de derechos e intereses desmedidos o excesivamente gravosos.

Los tres subprincipios deben aplicarse sucesivamente, primero, el subprincipio de adecuación, si la medida no es idónea o adecuada, la medida será inconstitucional y allí terminará el escrutinio, solo si la medida es idónea, se pasa al escrutinio del subprincipio de necesidad, si la medida supera este escrutinio, pasará a ser analizada finalmente, bajo el subprincipio de proporcionalidad en sentido estricto.

El principio de proporcionalidad es utilizado por la generalidad de las jurisdicciones constitucionales como parte del parámetro de control de la igualdad ante la ley, cuyo desarrollo inicial se realiza por la Corte Constitucional alemana y luego se expande en las jurisdicciones constitucionales europeas y latinoamericanas.

A manera ejemplar puede explicitarse la jurisprudencia del Tribunal Constitucional español. Por todas, la sentencia 222/1992, de 11 de di- 
ciembre, establece: "Una doctrina constante de este tribunal -tan reiterada que su cita es ya ociosa- viene estableciendo que los condicionamientos y límites que, en virtud del principio de igualdad, pesan sobre el legislador se cifran en una triple exigencia, pues las diferenciaciones normativas habrán de mostrar, en primer lugar, un fin discernible y legítimo, tendrán que articularse en términos no inconsistentes con tal finalidad, y deberán, por último, no incurrir en desproporciones manifiestas a la hora de atribuir a los diferentes grupos y categorías derechos, obligaciones o cualquiera otras situaciones jurídicas subjetivas".

Dicha perspectiva es asumida también por los tribunales constitucionales sudamericanos.

En efecto, la Corte Constitucional colombiana en el caso de la demanda de inconstitucionalidad del literal b del artículo 40 de la ley 48 de 1993 que aplicaba a todos los que hubieren hecho el servicio militar un aumento del $10 \%$ en el puntaje de exámenes estatales que los bachilleres deben presentar para acceder a la universidad, la Corte aplicó el principio de proporcionalidad y los subprincipios de adecuación, de necesidad y de proporcionalidad en forma estricta ${ }^{29}$.

Asimismo, el principio de proporcionalidad es asumido por la jurisprudencia del Tribunal Constitucional peruano, en caso de demanda de inconstitucionalidad de la impugnando la disposición que otorga una bonificación de hasta un $10 \%$ sobre la calificación total obtenida que se otorga a magistrados titulares (del Poder Judicial y Ministerio Público) que postulan al ascenso, respecto del grupo de abogados que no pertenece al Poder Judicial como asimismo, respecto de los magistrados suplentes y provisionales, al efecto, el Tribunal Constitucional señala: "31. (...) En esta misma línea, pero decantándose hacia una aplicación del principio de proporcionalidad y, conforme ya se sostuvo en la Sentencia recaída en el Exp. $N^{\circ}$ 0048-2004-PI/TC (fundamento $N^{\circ} 65$ ), este Colegiado considera que el principio que ha de emplearse para examinar si un tratamiento diferente establecido por una norma comporta un trato discriminatorio, es el principio de proporcionalidad".

"32. De esta forma, el principio de proporcionalidad que normalmente es empleado para examinar las intervenciones legislativas en los derechos constitucionales, abora, es proyectado para examinar el supuesto concreto de una eventual contravención del derecho-principio de igualdad"30.

El Tribunal Constitucional peruano analizó el artículo $7^{\circ}$ de la Ley 27.755 que establecía un registro legalizado por notario público en vez de una escritura pública para registrar el derecho de propiedad. Así el tribunal se preguntó por la finalidad de la norma cuestionada, señalando: 
"es reconocible la intención del legislador, quien a través del formulario registral, procura crear para los propietarios de escasos recursos una vía menos costosa para inscribir su derecho. El fin perseguido, por lo pronto, aparece como constitucionalmente legítimo, pues se pretende dotar al derecho de propiedad de las garantías suficientes para su pleno desarrollo, a través del registro mis$m 0^{\prime 31}$.

Luego, aplicó el test de proporcionalidad determinando:

"para concluir la proporcionalidad de la disposición cuestionada, no es suficiente la legitimidad del propósito buscado, ni tampoco la adecuación de la medida al fin perseguido. Es imprescindible valorar la necesidad de que sea esa medida la utilizada y no otra la que pueda sacrificar en menor grado el principio constitucional comprometido, en este caso la seguridad jurídica. A efectos de determinarse la necesidad o no de la medida adoptada, es del caso preguntarse cuál es el verdadero grado de afectación que sufre el principio de seguridad jurídica, cuando se propone como alternativa la utilización del formulario registral legalizado por el notario público, en lugar de la escritura pública"32.

"Comoquiera que la elección entre diversas alternativas se encuentra dentro de la esfera de discrecionalidad que la Constitución ha brindado al Poder Legislativo, este tribunal ba declarado que una medida será innecesaria o no satisfacerá este segundo subprincipio cuando la adopción de un determinado medio significa, o importa, un sacrificio desmesurado o manifiestamente innecesario, del derecho limitado"33.

Para luego precisar:

"si bien el formulario registral legalizado por notario no goza de la solemnidad de una escritura pública, se ha optado por una medida que no termina por desvirtuar la seguridad jurídica, sino que, respetándola dentro de términos todavía razonables, presenta una opción legislativa proporcional frente al fin legítimo, que se pretende alcanzar"34.

A su vez, en otro caso, el Tribunal Constitucional peruano aplicando el principio de proporcionalidad en sentido estricto determinó:

"el principio de proporcionalidad, stricto sensu, para que una injerencia en los derechos fundamentales sea legítima, el grado de realización del objetivo de esta debe ser, por lo menos, equivalente o proporcional al grado de afectación del derecho fundamental, comparándose dos intensi-

\footnotetext{
31 Sentencia del Tribunal Constitucional del Perú, Exp. N 0016-2002-AI/TC, de fecha 30 de abril de 2003 , fundamento jurídico $6^{\circ}$. Sentencia del Tribunal Constitucional del Perú, Exp. N 0016-2002-AI/TC, de fecha 30 de abril de 2003, fundamento jurídico $9^{\circ}$.

33 Sentencia del Tribunal Constitucional del Perú, Exp. N ${ }^{\circ}$ 0016-2002-AI/TC, de fecha 30 de abril de 2003 , fundamento jurídico $6^{\circ}$.

34 Sentencia del Tribunal Constitucional del Perú, Exp. N 0016-2002-AI/TC, de fecha 30 de abril de 2003, fundamento jurídico $9^{\circ}$.
} 
dades o grados: el de la realización del fin de la medida examinada y el de la afectación del derecho fundamental" 35 .

Asimismo, es necesario precisar como señala Villacorta, que en el ámbito del análisis de proporcionalidad como mandato derivado del principio de igualdad se distingue en un punto importante del análisis de la proporcionalidad llevada a cabo respecto a los derechos fundamentales de libertad, ya que el control de proporcionalidad debe adaptarse al principio de igualdad, ya que el asunto no es determinar la intromisión en el derecho fundamental, sino la proporcionalidad del tratamiento desigual, la proporcionalidad de la carga relacionada con la desigualdad de trato, lo que exige establecer al legislador motivos objetivos de diferenciación de naturaleza tal que justifique la desigualdad de $\operatorname{trato}^{36}$.

Esta perspectiva lleva a considerar que el principio de proporcionalidad solo se aplica a los tratamientos legislativos que persiguen fines externos donde el tratamiento desigual y la obtención del fin externo implica una relación de fines y medios auténtica, en la medida que "la igualdad de tratamiento en sentido normativo y la persecución de fines externos es susceptible de ser considerada como una relación de bienes jurídicos que colisionan" 37 .

Asimismo, parece necesario especificar que el principio de proporcionalidad debe aplicarse con diferentes intensidades, materia que en la doctrina alemana ha tratado R. Alexy ${ }^{38}$, que debe tener en consideración "la seguridad que ofrezcan las premisas empíricas analíticas y normativas relevantes, y de acuerdo con la intensidad de la injerencia de los poderes públicos en el derecho fundamental objeto de consideración ${ }^{39}$.

En tal perspectiva, puede sostenerse que mientras sea mayor o más intensa la injerencia en el derecho fundamental y más seguras sean las premisas relevantes, debe ser más estricto el escrutinio en base al principio de proporcionalidad.

La Corte Constitucional colombiana ha asumido la matización de la intensidad del control en base al principio de proporcionalidad, que tiene sus raíces en la Jurisprudencia de la Corte Suprema norteamericana res-

Sentencia del Tribunal Constitucional del Perú, Exp. $\mathrm{N}^{\circ}$ 2235-2004-AA/TC, fundamento jurídico $6^{\circ}$.

36 Villacorta MANCEBo, Luis. "Principio de igualdad y legislador: arbitrariedad y proporcionalidad como límites", en Revista de Estudios Políticos $N^{\circ} 130$, octubre-diciembre 2005, Centro de Estudios Políticos y Constitucionales, Madrid, 2005, pág. 72. cionalidad como límites", en Revista de Estudios Políticos $N^{\circ} 130$, octubre-diciembre 2005, Centro de Estudios Políticos y Constitucionales, Madrid, 2005. p. 73. Constitucional $N^{\circ} 66$, Madrid, ED Centro de Estudios Constitucionales.

39 Bernal Pulido, Carlos. 2005. El derecho de los derechos. Bogotá. Ed. Universidad Externado de Colombia, p. 265. 
pecto de la aplicación de la equal protection, que se encuentra en la decimocuarta enmienda, que como señala la Corte Constitucional colombiana "se funda en la existencia de distintos niveles de intensidad en los 'escrutinios' o 'tests' de igualdad (estrictos, intermedios o débiles)" ${ }^{40}$. La Corte Constitucional colombiana ha precisado que la aplicación de la escala de intensidades en el enjuiciamiento de la igualdad busca amoldar "la intervención de la jurisdicción constitucional en la órbita de competencias del legislador" a las exigencias del principio democrático y la separación de las ramas del poder público ${ }^{41}$.

Para la Corte Constitucional colombiana, el escrutinio débil, determina que un acto jurídico será declarado constitucional si el trato diferente que se enjuicia es "una medida potencialmente adecuada para alcanzar el propósito que no esté prohibido por el ordenamiento jurídico" ${ }^{42}$. En tal perspectiva, el escrutinio débil exige que el trato diferente tenga un objetivo legítimo, y que el trato legislativo sea adecuado para alcanzarlo y que no esté prohibido por la Carta Fundamental. El trato será inconstitucional si su objetivo está prohibido por la Constitución o si su tratamiento legislativo es manifiestamente inadecuado para alcanzar el fin legítimo constitucional ${ }^{43}$.

El escrutinio estricto, que proviene de la jurisprudencia norteamericana sobre el principio de la igualdad gestada en la década de los años sesenta del siglo pasado se desarrolló a partir de la constatación de que el racional basis-test no era adecuado para el escrutinio de los tratos diferenciados que afectaban a grupos que habían sido tradicionalmente discriminados y que, por tal causa, merecían recibir una protección especial de parte del Estado norteamericano. El escrutinio estricto se aplica cuando un trato diferenciado se funda en criterios sospechosos como la raza, la condición social, la orientación sexual, la edad o la minusvalía. La Corte colombiana aplicó el escrutinio estricto a los criterios potencialmente discriminatorios, considerando tales los que aparecen incluidos en los mandatos de igualdad tipificados constitucionalmente, los que restringen derechos fundamentales y los que afectan de manera desfavorable a minorías o grupos sociales que se encuentran en debilidad manifiesta, con especial deber de protección de parte del Estado, a ellos se han agregado, aquellas diferenciaciones que se fundan en rasgos permanentes de las personas de las cuales ellas no pueden prescindir por voluntad propia a riesgo de perder su identidad, las que afectan a grupos históricamente sometidos a menosprecio y prácticas discriminatorias, y aquellos

\footnotetext{
40 Sentencia de la Corte Constitucional colombiana, C-093 de 2001.

41 Sentencia de la Corte Constitucional colombiana, C-673 de 2001.

42 Sentencia de la Corte Constitucional colombiana, Sentencia C-093 de 2001.

43 Sentencia de la Corte Constitucional colombiana, Sentencia C-445 de 1995.
} 
que se funden en criterios que por sí mismos no posibiliten efectuar una distribución o reparto racional y equitativo de bienes, derechos o cargas sociales $^{44}$. En tales casos la constitucionalidad de la medida que establece un trato diferenciado debe cumplir dos exigencias: que la medida persiga un fin constitucionalmente imperioso o fin imperioso para la sociedad o el Estado y que la medida sea indispensable para alcanzarlo, siendo la única o aquella más idónea para el logro del fin.

El escrutinio intermedio fue desarrollado por la jurisprudencia norteamericana en la década de los setenta del siglo pasado, situándose a medio camino entre el escrutinio débil y el escrutinio estricto, aplicándose a los casos en que el Estado concreta diferencias fundadas en criterios sospechosos para intentar lograr una igualación de oportunidades para grupos tradicionalmente discriminados, se trata de las medidas positivas o de discriminación inversa. La Corte Constitucional colombiana aplica el escrutinio intermedio cuando la medida o norma puede afectar el goce de un derecho constitucional considerado no fundamental o cuando existe un indicio de arbitrariedad que se refleja en la afectación grave de la libre competencia ${ }^{45}$.

La misma perspectiva con matizaciones es asumida por el Tribunal Constitucional peruano, su jurisprudencia precisa:

“35. Intensidad de la intervención. La intervención en el principio de igualdad puede presentar diferentes grados o intensidades. Ello puede conceptualmente representarse en una escala de tres niveles:

- Intensidad grave

- Intensidad media

- Intensidad leve

a) un intervención es de intensidad grave cuando la discriminación se sustenta en alguno de los motivos proscritos por la propia Constitución (artículo $2^{\circ}$, inciso 2: origen raza, sexo, idioma, religión, opinión, condición económica) y, además tiene como consecuencia el impedimento del ejercicio o goce de un derecho fundamental o un derecho constitucional.

b) Una intervención es de intensidad media cuando la discriminación se sustenta en alguno de los motivos proscritos por la propia Constitución (artículo $2 \mathrm{~N}^{\circ}$ 2: origen raza, sexo, idioma, religión, opinión, condición económica) y, además, tiene como consecuencia el impedimento del ejercicio o goce de un derecho de rango meramente legal o el de un interés legítimo. 
c) Una intervención es de intensidad leve cuando la discriminación se sustenta en motivos distintos a los proscritos por la propia Constitución y, además tiene como consecuencia el impedimento del ejercicio o goce de un derecho de rango meramente legal o el de un interés legítimo.

“36. La relevancia de la determinación de la intensidad de la intervención en la igualdad radica en que se trata de una variable a ser empleada en el análisis del principio de necesidad y de proporcionalidad en sentido estricto. En efecto, por una parte, en el análisis del subprincipio de necesidad se ha de proceder a una comparación de las intensidades de la intervención del medio adoptado por el legislador y del medio hipotético para, según ello, examinar si este último es de menor intensidad o no respecto del primero. Por otra parte, en el examen de ponderación o proporcionalidad en sentido estricto, la intensidad de la intervención en la igualdad constituye una variable que ha de compararse con la intensidad o grado de realización u optimización del fin constitucional".

La gradación del escrutinio de igualdad tiene una claridad analítica menor que el principio de proporcionalidad, ya que en este análisis solo son relevantes la legitimidad del objetivo constitucional y la idoneidad de la medida que establece la diferenciación, no teniendo en consideración que tal objetivo podría ser alcanzado por un medio igualmente idóneo o más idóneo que no implicara la diferenciación (principio de necesidad), como asimismo, que la legitimidad de las diferenciaciones debe también depender de la relación existente entre la intensidad en que se alcanza el objetivo de la medida y la intensidades que se afecta el derecho a la igualdad y los demás derechos fundamentales afectados (principio de proporcionalidad en sentido estricto).

Finalmente, nos parece necesario señalar que la aplicación del test de proporcionalidad y el principio de proporcionalidad en sentido estricto no pueden llegar a desnaturalizar el derecho fundamental afectado en pro de un bien jurídico constitucional, ya que como señala nuestro artículo $19 \mathrm{~N}^{\circ} 26$, el legislador no puede afectar el contenido esencial del derecho constitucionalmente determinado, en efecto, dicha disposición constitucional asegura a todas las personas "la seguridad de que los preceptos legales que por mandato de la Constitución regulen o complementen las garantías que esta establece, o que las limiten en los casos que ello lo autoriza, no podrán afectar los derechos en su esencia, ni imponer condiciones, tributos o requisitos que impidan su libre ejercicio. 


\subsection{La carga de la prueba sobre la razonabilidad de la norma o el} carácter de relevante de las diferencias

Un primer problema en esta materia es que el juez no puede oponer su "razón" a la del legislador cuando se trata de pronunciarse sobre la validez de la ley y no solo de su aplicación.

En muchos casos, los Tribunales Constitucionales tienen implícito en su juzgamiento que el juez puede buscar en la conciencia jurídica de la comunidad el criterio que puede permitirle pronunciarse sobre la razonabilidad de la obra del legislador, conclusión que es corriente desde la formulación de esta doctrina en Alemania por Leibholz y Triepel.

El problema es cómo se expresa la conciencia jurídica de la comunidad cuando ella no lo hace a través de sus representantes, o ¿por qué el juez puede considerarse mejor intérprete de la conciencia jurídica de la comunidad que el legislador? Esto nos lleva al tema de la justicia constitucional y el principio de igualdad y a los distintos grados de intensidad del control constitucional jurisdiccional de la ley.

Esta última perspectiva lleva a fijar los criterios de determinación de las diferencias relevantes, lo cual requiere contar con un punto de referencia, el cual es el objetivo perseguido por el legislador. Esto, sin embargo, nos lleva a interrogarnos sobre si cualquier objetivo es aceptable o si el objetivo debe cumplir ciertas condiciones, y en este último caso, ¿cuales condiciones debe cumplir? Al respecto puede afirmarse que el objetivo no puede ser contrario a la Constitución y a los tratados de derechos humanos, debiendo además ser legítimo.

A su vez, si la desigualdad resulta de una distinción establecida por el legislador y cuya validez se niega, la carga de probar la razonabilidad de la diferencia corresponde a quien defiende la ley, pero como la igualdad también puede plantearse frente a un tratamiento legal que a juicio de quien lo impugna, ha ignorado diferencias significativas, es el impugnador quien debe aportar las razones por la que debió atribuirse relevancia jurídica a tales diferencias. En ambas situaciones, es el defensor de la ley el que deberá establecer las razones que avalan la razonabilidad, pero la diferencia está en que en el primer caso, la razonabilidad que debe ser probada es la diferencia establecida, mientras que en el segundo caso, lo que debe de demostrarse es la falta de razonabilidad o la discriminación o arbitrariedad de la diferenciación.

De acuerdo a todos los elementos antes enunciados como son la finalidad de la norma, su razonabilidad, la proporcionalidad entre medios y fines, la consideración particular de dicha sociedad y un cierto margen de acción que se reconoce al legislador, todos ellos constituyen elementos que el intérprete debe tener en consideración al momento de dictar su sentencia en el plano de la jurisdicción constitucional. De esta manera, el juez dispone de cierto nivel de discrecionalidad para configurar el 
ordenamiento jurídico pero dentro del marco de referencia explicitado, inteligible y fundado en principios.

\section{LAS MODALIDADES DE LA DISCRIMINACIÓN O LA DIFERENCIACIÓN ARBITRARIA}

Es posible establecer algunas clasificaciones sobre las modalidades de la discriminación.

Una primera clasificación puede basarse en el criterio de discriminaciones de iure o discriminación de facto. La primera se produce en el contenido de las normas jurídicas y puede hablarse de discriminación en el contenido de la norma jurídica, vale decir, si los criterios que utiliza la ley para distinguir están justificados y son razonables o no. La discriminación de facto se produce como consecuencia de la aplicación de la norma jurídica, sin que los preceptos jurídicos en sí mismos sean necesariamente discriminatorios, en otras palabras hay discriminación de facto cuando la norma jurídica no se aplica imparcialmente a todas las personas que se encuentran en la misma hipótesis, hay aquí, por lo tanto, un enjuiciamiento a la aplicación de la ley.

La igualdad en la aplicación de la ley implica una obligación para todos los órganos estatales mediante la cual no pueden aplicar la ley de manera diferente a personas que se encuentran en supuestos sustancialmente iguales.

La jurisdicción puede resolver, a su vez, casos en apariencia iguales con resultados diferentes, si se justifica la razonabilidad de la decisión en virtud de restablecer una igualdad auténtica o por particularidades de supuestos fácticos que justifiquen resultados diferentes.

Asimismo, también puede justificarse la variación de decisiones de los operadores jurisdiccionales en un cambio de perspectiva debidamente motivada, explicando las razones de hecho y de derecho del cambio de criterio. Así lo establece la doctrina y jurisprudencia comparada, a modo ejemplar señalaremos un fallo del Tribunal Constitucional español en sentencia 49 de 1982, la que establece que:

"La regla general de igualdad ante la ley... contempla, en primer lugar la igualdad en el trato dado por la ley o igualdad en la ley y constituye desde este punto de vista un límite puesto al ejercicio del Poder Legislativo, pero es asimismo igualdad en la aplicación de la ley, lo que impone que un mismo órgano no puede modificar arbitrariamente el sentido de sus decisiones en casos sustancialmente iguales y que cuando el órgano en cuestión considere que debe apartarse de sus precedentes tiene que ofrecer para ello una fundamentación suficiente y razonable".

Una segunda clasificación que puede establecerse respecto de las modalidades de la discriminación consiste en si está se produce por actos esporádicos o por actos sistemáticos, ya sea por agentes estatales o por personas privadas (individuos, asociaciones o entidades jurídicas). 


\subsection{La discriminación de género y de grupos históricamente pos- tergados}

Es necesario asumir mediante tal normativa la explícita prohibición de mantener determinadas diferenciaciones históricamente arraigadas y que han situado, tanto por la acción de los órganos estatales, como por la práctica social, a sectores de la población en posiciones marginales o altamente desventajosas, cuando no atentatorias contra la dignidad humana. Así ha ocurrido matizadamente con las diferencias de género y los pueblos originarios de nuestros países latinoamericanos.

Asimismo, en el ámbito de las diferencias de género, la doctrina norteamericana y española, la cual ha sido asumida por el Tribunal Constitucional español, ha incorporado algunas diferenciaciones que no podemos sino avalar como criterios de discernimiento y reconocimiento de discriminación. En efecto, se distingue entre discriminación directa e indirecta, asimismo, respecto de la primera se subdistingue entre discriminación directa expresa y discriminación directa oculta ${ }^{46}$.

La discriminación directa la define el Tribunal Constitucional español como aquel tratamiento diferenciado perjudicial en razón del sexo donde este sea objeto de consideración directa ${ }^{47}$, siendo la intención la que califica a esta discriminación. La misma sentencia precisa que la discriminación indirecta (disparate impact) es aquella en que la diferencia de trato es formalmente correcta y no aparece directamente vinculada al sexo pero genera unas consecuencias discriminatorias sobre un concreto colectivo por razón de su sexo, siendo el resultado lo que califica esta discriminación $^{48}$.

La perspectiva anterior debe ser matizada en el sentido de que algunas diferenciaciones basadas en el sexo no tienen reproche de inconstitucionalidad pero deben pasar por un escrutinio estricto y una sospecha de presunción de inconstitucionalidad. Algunos supuestos de diferenciación en base al sexo pueden considerarse constitucionales en el supuesto de puestos laborales vinculados directamente con el sexo (actrices, gendarmes en prisiones de mujeres, aseo en vestuarios o baños femeninos, entre otras hipótesis posibles).

Nuestro análisis, en todo caso, se centra en el análisis de las discriminaciones de iure, aquellas producidas por el legislador.

46

LÓpez Guerra, L. "Igualdad, no discriminación y acción positiva en la Constitución española de 1978. En VV.AA. Mujer y Constitución, Madrid. Ed Centro de Estudios Políticos y Constitucionales, p. 27.

47

Sentencia del Tribunal Constitucional español 145/1991, de 1 de julio. Citada por GóMEZ SÁNCHEZ, Yolanda. 2003. Op. cit. pp. 144- 145.

48 Ver AÑó, María José. Igualdad, diferencias y desigualdades. Fontamara, México. 2001. pp. 29-31. 


\section{LA TUTELA POSITIVA DE LA IGUALDAD O IGUALDAD PROMOCIONAL: LA IGUALDAD DE OPORTUNIDADES Y LAS ACCIONES POSITIVAS, AFIRMATIVAS O DE DISCRIMINACIÓN INVERSA}

Junto a la igualdad ante la ley que obliga a abstenerse de desarrollar cualquier diferencia arbitraria o discriminación, exige también una tutela positiva de la igualdad que deben tener presente por imperativo constitucional los órganos estatales, cuando los ordenamientos constitucionales establecen como principios básicos la igualdad de oportunidades, la remoción de obstáculos que impiden el desarrollo de la igualdad de oportunidades o la igualdad sustancial y no meramente formal, lo que implica un principio de solidaridad respecto de las personas o grupos sociales que se encuentran en situación de debilidad. Es lo que, en otras palabras, Bobbio denomina la función promocional del derecho ${ }^{49}$.

Nuestra Carta Fundamental en sus Bases de la Institucionalidad, artículo $1^{\circ}$, determina imperativamente, en su inciso $4^{\circ}$, que "El Estado está al servicio de la persona bumana y su finalidad es contribuir al bien común, para lo cual debe contribuir a crear las condiciones sociales que permitan a todos $y$ cada uno de los integrantes de la comunidad nacional su mayor realización espiritual y material posible, con pleno respeto a los derechos y garantías que esta constitución establece". Asimismo, el inciso final del mismo artículo dispone, "Es deber del estado (...).. promover la integración armónica de todos los sectores de la Nación y asegurar el derecho de las personas a participar con igualdad de oportunidades en la vida nacional".

Así, el sistema de valores y principios establecidos en las bases de la institucionalidad obligan a interpretar el texto constitucional y las leyes dictadas conforme al mismo con un carácter sistemático y finalista, lo que fundamenta lo que podemos denominar igualdad promocional.

En nuestra Sudamérica diversos tribunales constitucionales han recogido dicha perspectiva. Así a manera ejemplar puede señalarse la doctrina del tribunal constitucional peruano, el cual ha precisado:

"El principio de igualdad en el Estado constitucional exige del legislador una vinculación negativa o abstencionista y otra positiva o interventora. La vinculación negativa está referida a la ya consolidada jurisprudencia de este colegiado respecto de las exigencias de 'tratar igual a los que son iguales' $y$ 'distinto a los que son distintos', de forma tal que la ley, como regla general, tenga una vocación necesaria por la generalidad y la abstracción, quedando proscrita la posibilidad que el Estado, a través del legislador, pueda ser generador de factores discriminatorios de cualquier índole. Sin embargo, enfocar la interpretación del derecho a la igualdad desde una faz estrictamente liberal,

49 Boвbio, Norberto, Contribución a la teoría del derecho. Segunda edición. Ed. Debate. Ver el acápite "La función promocional del derecho". Madrid. 1990. 
supondría reducir la protección constitucional del principio de igualdad a un contenido meramente formal, razón por la cual es deber de este Colegiado, de los poderes públicos y de la colectividad en general, dotar de sustancia al principio de igualdad reconocido en la Constitución. En tal sentido, debe reconocerse también una vinculación positiva del legislador a los derechos fundamentales, de forma tal que la ley esté llamada a revertir las condiciones de desigualdad o, lo que es lo mismo, a reponer las condiciones de igualdad de las que la realidad social pudiera estarse desvinculando, en desmedro de las aspiraciones constitucionales" 50 .

Los preceptos legales que definen reglas de discriminación inversa o medidas afirmativas pueden conceptualizarse como aquellas que establecen temporalmente un trato diferenciado a favor de sectores en objetiva situación de marginación, con la finalidad de lograr una igualación de oportunidades en forma real, su adecuada integración social y acceso a los derechos formalmente consagrados en el ordenamiento jurídico ${ }^{51}$.

En el derecho norteamericano las afirmative acition han sido conceptualizadas por la Comisión Norteamericana de Derechos Civiles, como "cualquier medida, más allá de la simple terminación de una práctica discriminatoria presente o pasada o para impedir que la discriminación se produzca en el futuro" 52 .

El origen de las acciones positivas se encuentra en el derecho norteamericano, las cuales buscan superar una historia de discriminación racial y sexual desde su constitución como nación, que opera en la segunda mitad del siglo XX para revertir las situaciones de marginación y discriminación ${ }^{53}$.

Como señalaba Bidart Campos la discriminación positiva o discriminación inversa:

"Es algo que aparentemente puede presentarse como lesivo de la igualdad y, muy lejos de ello, es o puede ser un trato razonable para alcanzarla, es la llamada discriminación "inversa". En determinadas circunstancias que con suficiencia aprueben el test de la razonabilidad, resulta constitucional favorecer a determinadas personas de ciertos grupos sociales en mayor proporción que a otros, si mediante esa "discriminación" se procura compensar y equilibrar la marginación o el relegamiento inegualitario que recae sobre aquellas personas que con la discriminación inversa se benefician. Se denomina precisamente discriminación

so Sentencia del tribunal Constitucional del Perú Exp. N 0001/0003-2003-AI/TC, fundamento jurídico $11^{\circ}$.

51 En sentido similar, Eguiguren Praeli, Francisco. Principio de igualdad y derecho a la no discriminación. En Estudios Constitucionales, ARA Editores, Lima, 2002. p. 110.

52 MARTIN VIDA, M.A. Fundamentos y limites constitucionales de las medidas de acción positiva. ED. Civitas, Madrid, 2002, p. 35.

53 Sobre la materia ver, TURNER, R. The past and present of affirmative action. Ed. Quorum Books, New York. 1991; Rosenfeld, Michel. Affirmative action and justice. Yale University Press. New Haven, 1991. 
inversa porque tiene a superar la desigualdad discriminatoria del sector perjudicado por el aludido relegamiento" 54 .

El problema se presenta muchas veces por el hecho de que los grupos en desventaja o debilidad social están definidos precisamente por algunos de aquellos criterios cuya utilización jurídica está expresamente prohibida por la Constitución y los tratados internacionales, como son por ejemplo el sexo y la raza. "El legislador se ve así colocado en una aporía, de la que solo puede salir, con la ayuda del juez, mediante una derogación parcial de la norma probibitiva o, la menos, una considerable reducción de su eficacia. La justificación de la razonabilidad de la decisión resulta, sin embargo, especialmente difícil, tanto para el legislador como para el juez, mediante la apelación a la "conciencia jurídica de la comunidad" pues, como fácilmente se entiende, situaciones de este género solo pueden producirse cuando la conciencia social está escindida, de manera que, en tanto que una parte de la sociedad actúa de una manera discriminatoria, otra parte intenta corregir mediante el uso del poder los efectos de tal discriminación" 55 .

Este es uno de los grandes problemas a los cuales se encuentra enfrentada la jurisdicción y la jurisprudencia constitucional, ya que aquí se manifiesta una tensión ente la política y el derecho y es en dicho límite donde frecuentemente se establecen las acusaciones de activismo judicial o de abdicación del juez ante la arbitrariedad del legislador. Es aquí también donde el juez debe adoptar una actitud y prudencia propia de quien carece de un poder de impulsión jurídico y en algunos casos poner en acción su autolimitación. En todo caso la actividad del juez o del tribunal solo será legítima si se apoya en una misma interpretación de las normas constitucionales, cuando estas consideran como valor o principio de igualdad de oportunidades o la remoción de los obstáculos para el logro de la misma, principios que, de acuerdo a la Constitución, deben ser implementados o promovidos por el Estado y sus órganos.

En este sentido, diversos tribunales constitucionales han desarrollado una jurisprudencia consistente, entre ellos, señalaremos algunas sentencias del Tribunal Constitucional español, colombiano y peruano.

El Tribunal Constitucional de Colombia, en sentencia T 402/92, asume esta perspectiva señalando:

"El principio de igualdad de oportunidades juega un papel neurológico en la tarea de mantener y promover un orden justo, en una sociedad que además de la pobreza se caracteriza por una inquisitiva distribución de recursos. La obligación del Estado de promover las condiciones para alcanzar una igualdad real y efectiva solo podrá verse cumplida mediante 
el respeto e igual consideración de todas la personas en el diseño y funcionamiento de las instituciones públicas. Tratándose de un menor de edad, se espera que su permanencia en una entidad educativa sea garantizada por encima de las decisiones arbitrarias de la autoridad de turno con poder decisorio para otorgar y denegar cupos de estudios".

A su vez, el Tribunal Constitucional peruano ha determinado:

“(...) en los hechos no son pocas las ocasiones en que un determinado grupo de individuos se encuentran postergados en el acceso, en igualdad de condiciones, a las mismas oportunidades. Tal constatación genera en el Estado la obligación de tomar medidas pertinentes a favor de los postergados, de forma de que sea posible reponer las condiciones de igualdad de oportunidades a las que la constitución aspira" ${ }^{56}$, siendo así un "deber del Estado instaurar las condiciones para despejar los obstáculos que generen tal desigualdad de oportunidades" 57.

El mismo Tribunal Constitucional del Perú, también ha precisado que: "La vinculación positiva (al principio de igualdad) supone la exigencia de revertir las condiciones de desigualdad, o de reponer las condiciones de igualdad de las que la realidad social pudiera estarse desvinculando, en desmedro de las aspiraciones constitucionales, a través de las acciones positivas cuyo fin sea promover la igualdad real y efectivamente la igualdad sustancial entre los individuos. Ello a efectos de configurar materialmente una simetría de oportunidades para todos los seres humanos.

"En este sentido, no se considera como discriminaciones aquellas acciones legislativas que establezcan tratos diferenciados con el objeto de promover la igualdad real de oportunidades, a condición de que dicha acción afirmativa esté sujeta a la regla de temporalidad.

"La acción afirmativa del Estado consiste en la adopción de medidas que remuevan los obstáculos que restringen, en la praxis, la plena vigencia del principio de igualdad" 58 .

En una perspectiva moderada, el Tribunal Constitucional español, en sentencia $\mathrm{N}^{\circ} 27$ de 1981, había establecido que:

“... la finalidad de promover la libertad del individuo, y de los grupos en que se integra, en ocasiones, exige una política legislativa que no puede reducirse a la pura igualdad ante la ley".

El Tribunal Constitucional español en sentencia $N^{\circ} 14$ de 1983 , señaló que:

\footnotetext{
56 Sentencia del Tribunal Constitucional del Perú, Exp. N 0016-2002-AI, fundamento jurídico $11^{\circ}$.

57 Sentencia del Tribunal Constitucional del Perú, Exp. N 0016-2002-AI, fundamento jurídico $12^{\circ}$.

58 Sentencia del Tribunal Constitucional del Perú, Exp. N 2945-2003-AA/TC, fundamento jurídico 8.
} 
"debe admitirse como constitucional el trato distinto que recaiga sobre supuestos de becho que fueran desiguales en su propia naturaleza, cuando su función contribuya al restablecimiento de la igualdad real a través de un diferente régimen jurídico, impuesto precisamente para hacer posible el principio de igualdad, lo que indudablemente acontece con la desigualdad originaria que mantienen el empresario y el trabajador, debida a la distinta y generalmente profunda condición económica de ambos y a la posición de primacía y respectiva dependencia o subordinación del uno respecto al otro, que precisamente trata de equilibrar el derecho laboral compensador e igualitario, lo que tiene el fundamental apoyo del art. 9.2 de la Constitución".

A su vez, el mismo Tribunal Constitucional en sentencia $\mathrm{N}^{\circ} 189$ de 1987, establece que:

"los poderes públicos deben buscar los medios para lograr que la igualdad se acerque a los principios rectores del Capítulo Tercero del Título I de la Constitución, y singularmente para promover condiciones de igualdad real y efectiva (art. 9.2 CE). Pero entre tales poderes públicos son el legislador y el gobierno quienes tienen el poder de iniciativa, y no este Tribunal".

También en sentencia $N^{\circ} 19$ de 1988, el Tribunal Constitucional español dispuso lo siguiente:

"Puede imponer este precepto... la adopción de normas especiales que tiendan a corregir los efectos dispares que, en orden al disfrute de bienes garantizados por la Constitución, se sigan de la aplicación de disposiciones generales en una sociedad cuyas desigualdades radicales han sido negativamente valoradas por la propia Norma Fundamental".

Asimismo en sentencia $N^{\circ} 216$ de 1991 señaló el mismo Tribunal que: "La incidencia del mandato contenido en el art. 9.2 sobre el que... encierra el art. 14 supone una modulación de este último, en el sentido, por ejemplo, de que no podrá reputarse de discriminatoria y constitucionalmente probibida-antes al contrario - la acción de favorecimiento, siquiera temporal, que aquellos poderes emprendan en beneficios de deteminados colectivos bistóricamente preteridos $y$ marginados".

A su vez la sentencia del mismo Tribunal Constitucional $\mathrm{N}^{\circ} 3$ de 1993 estableció que: "La referencia al sexo en el artículo 14 implica la decisión constitucional de acabar con una bistórica situación de inferioridad atribuida a la mujer, siendo inconstitucional la diferenciación normativa basada en dicho criterio. Con todo, en la perspectiva del artículo 9.2 CE, de promoción de las condiciones de igualdad no se considera discriminatorio que, a fin de promover una real y efectiva equiparación de la mujer con el hombre, se adopten ciertas medidas de acción positiva en beneficio de la mujer. La desigual situación de partida que padece la mujer puede ser corregida mediante este tipo singular de medidas, y al mismo tiempo, como ha señalado la STC 28-1992, mediante la eliminación de normas protectoras del trabajo femenino que puedan suponer en sí mismas una barrera al acceso real de la mujer al mundo del trabajo, en condiciones de igualdad con los varones". 
Por último, el Tribunal Constitucional español ha establecido que: "una Estado social y democrático de derecho, que propugna entre los valores superiores de su ordenamiento jurídico la justicia y la igualdad (art. 1.1 de la CE) y en el que se encomienda a todos los poderes públicos el promover las condiciones para que la igualdad del individuo y de los grupos en que se integra sean reales y efectivas (art. 9.2 de la CE) a de complementar aquel sistema de determinación del mínimo salarial (negociación colectiva) estableciendo desde los poderes públicos a los que compete la gobernación unos techos salariales mínimos" 59 .

Así, diversas constituciones establecen el empeño de toda la comunidad nacional y de todos sus órganos, en remover los obstáculos de orden económico y social que limiten la igualdad efectiva de las personas, alcanzando un conjunto básico esencial de condiciones de vida en el pleno material, moral y espiritual. Ello constituye una indicación finalista que permite concretar aquella orientación en la función legislativa hacia fines sociales.

De esta forma, la igualdad de oportunidades o la igualdad sustancial justifica las excepciones que debe experimentar la igualdad formal con vistas a eliminar los efectos de las discriminaciones del pasado o las disparidades de hechos originados en la injusticia de la naturaleza, posibilitando acciones positivas o de discriminación inversa ${ }^{60}$.

En este sentido, la Constitución chilena, además de fijar en el artículo $1^{\circ}$ inciso $4^{\circ}$ el bien común como fin y tarea del Estado, como asimismo, en el inciso final del mismo artículo el deber del Estado "de promover la integración armónica de todos los sectores de la Nación y asegurar el derechos de las personas a participar con igualdad de oportunidades en la vida nacional".

Respecto de esta disposición el Tribunal Constitucional chileno, en sentencia de fecha 13 de septiembre de 1983, Rol $\mathrm{N}^{\circ} 19$, consideró:

"Que el artículo $1^{\circ}$ de la Carta Fundamental es de un profundo y rico contenido doctrinario, que refleja la filosofía que inspira nuestra Constitución y orienta al intérprete en su misión de declarar y explicar el verdadero sentido y alcance del resto de la preceptiva constitucional", y agrega luego "el objeto de este precepto es destacar algunas de las funciones más relevantes que debe ejecutar el Estado en procura de obtener su finalidad básica, cual es "promover el bien común", concepto este último que define el inciso cuarto del mismo precepto como el conjunto "de las condiciones sociales que permitan a todos y a cada uno de los integrantes de la comunidad nacional su mayor realización espiritual y material

RUBIO LLORENTE, Francisco. Derechos fundamentales y principios constitucionales. Op. cit. pp. 63-64.

60 Ver MARTín VIDA, M.A. Fundamento y límites constitucionales de las medidas de acción positiva. Ed. Civitas. Madrid, 2002. 
posible, con pleno respeto a los derechos y garantías que esta Constitución establece". Este y no otro es, en esencia, el contenido y alcance del inciso final del artículo $1^{\circ}$ de la Carta Fundamental. En consecuencia, no cabe duda que, conforme a este precepto, los titulares e integrantes de los órganos del Estado deben realizar estas funciones básicas a fin de alcanzar la finalidad suprema, el bien común".

Asimismo, en esta perspectiva igualadora de oportunidades, la Carta Fundamental contempla un conjunto de otras disposiciones, entre las cuales cabe destacar, el artículo $19 \mathrm{~N}^{\circ} 3$ que garantiza asistencia judicial a los pobres; el artículo $19 \mathrm{~N}^{\circ} 10$, que asegura la educación básica para todos en forma gratuita; el artículo $19 \mathrm{~N}^{\circ} 20$, que establece la progresividad del sistema tributario; y el artículo $19 \mathrm{~N}^{\circ} 24$ que asegura la función social de la propiedad.

A su vez, las Constituciones de Colombia, art. 13; España, art. 9; Chile, art. 1, inciso 3 y final; Ecuador art. 19; El Salvador, art. 1; Guatemala, art. $2^{\circ}$; Paraguay, art. 46; entre otras, facultan para adoptar medidas tendientes a remediar la situación desventajosas en que se encuentran los sectores sociales más débiles y que les pongan en situación de igualdad de oportunidades con los demás miembros de la sociedad.

El intérprete constitucional debe tener en cuenta así los objetivos o fines establecidos constitucionalmente, la adecuación de las medidas legislativas destinadas a alcanzar tales fines, reconociendo el margen de acción que es propio de los órganos gubernamentales políticos, pero también protegiendo el derecho, ya que no es suficiente que la autoridad política diga que está promoviendo el interés público, para que efectivamente ello sea así y su decisión sea constitucional.

Así podemos concluir que el Estado y sus órganos no solo deben abstenerse de discriminar, sino que además tienen el deber de promover a través de acciones positivas específicas legislativas y administrativas, la efectiva igualdad de oportunidades de toda la población.

La adopción de acciones positivas o de discriminación inversa, son constitucionalmente legítimas para alcanzar niveles de equidad o situar en situación justa a grupos sociales tradicionalmente discriminados negativamente, todo lo cual requiere que la norma legislativa sea idónea para lograr el objetivo de eliminar la inequidad, cuya situación fáctica debe estar objetivamente establecida, siendo dicha normativa transitoria, solo mientras permanezca la desigualdad inequitativa ${ }^{61}$.

Ello supone, en algunos casos, consagrar una protección especial a las personas o grupos que, por sus condiciones físicas, mentales, cultura-

61 En el mismo sentido, Fernández GonZÁlez, Miguel Ángel. El principio de igualdad constitucional ante la ley. Ed. ConoSur Ltda., 2001. Santiago, pp. 72-73. 
les o económicas se encuentran en situación de discriminación o que agravan la situación de debilidad de otros individuos o grupos.

En tal sentido, se ha pronunciado el Tribunal Constitucional peruano, el cual ha precisado que:

“(...) cuando el artículo $103^{\circ}$ de la Constitución prevé la imposibilidad de dictar leyes especiales 'en razón de la diferencia de personas', abunda en la necesaria igualdad formal prevista en el inciso $2^{\circ}$ del artículo $2^{\circ}$, según la cual el legislador no puede ser generador de diferencias sociales; pero en modo alguno puede ser interpretado de forma que se limite el derecho y el deber del Estado de, mediante 'acciones positivas' o de 'discriminación inversa, ser promotor de la igualdad sustancial entre los individuos" 62 .

Ello lleva a plantear la necesidad de tener presente en el tema de la igualdad, el principio de igual consideración, el que obliga en el caso de medidas adoptadas por la administración en la definición de políticas sociales, económicas y culturales, a considerar violatorias del principio de igualdad las medidas que excluyan o pasaran por alto algunos de los posibles beneficios, los cuales necesariamente deben tenerse presentes, aun cuando tengan poca presencia, influencia o poder. El uso de este criterio permitirá reducir los riesgos de que un órgano estatal tomara decisiones arbitrarias basadas en criterios sin justificación racional, a su vez, ello haría más responsables a los funcionarios directivos que deben tomar las decisiones, al serles exigibles un análisis más cuidadoso que no deje fuera a ciertos grupos que debieran estar comprendidos dentro de los beneficiarios, como asimismo, cuidando de no gravar excesivamente a otros.

Consideramos conveniente precisar que un sector de la doctrina distingue en base a la intensidad de las medidas adoptadas y el resultado perseguido, en materia de diferencias de género, entre las acciones positivas en sentido estricto y las medidas de discriminación inversa ${ }^{63}$.

Las medidas de acciones positivas en sentido estricto buscan situar al sexo minusvalorado en el mismo punto de partida que aquel en que se encuentra el otro en el ejercicio de sus derechos o en la obtención de bienes y servicios.

Las medidas de discriminación inversa serían aquellas que inciden directamente en el resultado estableciendo condiciones o requisitos que pueden llevar a provocar una diferencia notable entre los sexos cuyo único fundamento es la igualdad de resultado que se persigue con dicho tipo de acción.

62 Huerta, Luis Alberto. El derecho a la igualdad. Revista Pensamiento Constitucional, año XI $N^{\circ} 11$, Ed. Pontificia Universidad Católica del Perú, Lima, 2005. p. 331.

63 JIMÉNEZ GLUCK, D. Una manifestación polémica del principio de igualdad: acciones positivas moderadas y medidas de discriminación inversa. Ed Tirant lo Blanch. Valencia. 1999. 
No está de más señalar, para terminar este párrafo, que el Tratado de Amsterdam que modificó el artículo 119 del Tratado de la Comunidad Europea, actual artículo 141 de dicha convención, en uno de sus apartados determina:

"Con el objeto de garantizar en la práctica la plena igualdad entre hombres y mujeres en la vida laboral, el principio de igualdad de trato no impedirá a ningún Estado miembro mantener o adoptar medidas que ofrezcan ventajas concretas destinadas a facilitar al sexo menos representado el ejercicio de actividades profesionales o a evitar o compensar desventajas en sus carreras profesionales"

\section{CONSIDERACIONES FINALES}

De esta manera, la igualdad se constituye hoy en una condición general de validez de las leyes y en un derecho subjetivo público de las personas.

El derecho a la igualdad ante la ley y en la ley constituye un derecho subjetivo, ya que es una facultad o atributo inherente a toda persona a no ser objeto de discriminación, vale decir, de un trato basado en diferencias arbitrarias.

La discriminación es así la diferencia arbitraria, es la desigualdad de tratamiento de las personas carente de justificación objetiva y razonable, como asimismo, es el tratamiento igual de personas que se encuentran en situaciones en que hay diferencias jurídicas relevantes, que obligarían a un tratamiento diferenciado.

El derecho a la igualdad tiene un núcleo duro que es toda diferencia basada en cualquier dimensión subjetiva hecha en base al sexo, la raza, la creencias religiosas, las opiniones políticas, $u$ otro criterio prohibido expresamente por los tratados internacionales o por la Constitución, la ley se presume inconstitucional mientras la autoridad no demuestre lo contrario. Tal diferenciación es sospechosa de inconstitucionalidad, debiendo ser sometida a un riguroso análisis de razonabilidad y proporcionalidad, el cual en última instancia, debe ser determinado por parte de la jurisdicción constitucional, o la corte internacional de derechos humanos competente, en su caso.

En los demás casos, la diferenciación realizada por la ley en base a elementos objetivos es legítima, siempre que se acredite:

a) La relevancia de la diferenciación.

b) La acreditación de un objetivo o finalidad constitucionalmente legítima que fundamente o valide la diferenciación, dotándola de razonabilidad.

c) La aplicación en su caso del principio de proporcionalidad, con sus subprincipios de idoneidad o adecuación, de necesidad y de proporcionalidad en sentido estricto. 
d) El respeto del contenido esencial del derecho.

e) La prohibición de afectar el contenido esencial del derecho.

Sobre dicha base puede concretarse luego el principio de protección, que está diseñado con el objeto de lograr, a través de acciones positivas, una igualdad efectiva de oportunidades y la remoción de los obstáculos que se oponen a ella.

La igualdad deja de ser así un principio puramente formal, debiendo considerar las situaciones concretas y reales en que se encuentra cada grupo social, buscando lograr una igualdad efectiva de oportunidades.

\section{BIBLIOGRAFÍA}

- Alexy, R.: Teoría de los derechos fundamentales. Ed. Centro de Estudios Constitucionales. Madrid, 1997.

: "Epílogo a la teoría de los derechos fundamentales", Revista Española de Derecho constitucional $N^{\circ} 66$, Ed. Centro de Estudios Constitucionales. Madrid, 2002.

- Andrade G., Carlos: Elementos de Derecho Constitucional Cbileno. Ed. Jurídica de Chile. Santiago, 1963.

- AÑón, María José: Igualdad, diferencias y desigualdades. Fontamara. México. 2001.

- BARNES, J.: "Introducción al principio de proporcionalidad en el Derecho Comparado y comunitario", en Revista de Administración Pública $N^{\circ}$, España. 1994.

- $\quad$ :Introducción al principio de proporcionalidad", en Cuadernos de Derecho Público $N^{\circ}$ 5, España. 1998.

- Bernal Pulido, Carlos: El principio de proporcionalidad y los derechos fundamentales. ED. Centro de Estudios Políticos y Constitucionales. Madrid, 2003.

de Colombia. Bogotá, 2005.

- Bidart Campos, Germán: Tratado elemental de Derecho constitucional argentino. Tomo I. Buenos Aires. 1993.

- Blanc, N.; Nogueira, H.; Pfeffer, E.; y Verdugo, M.: La Constitución chilena. Tomo I. Ed. Centro de Estudios y Asistencia Legislativa. Universidad Católica de Valparaíso, Chile. 1990.

- Bobbio, Norberto. Contribución a la teoría del derecho. Segunda edición. Ed. Debate. Madrid. 1990.

- Bulnes Aldunate, Luz. "La igualdad ante la ley". Revista Gaceta Jurídica $N^{\circ} 49$, Editorial ConoSur. Santiago, 1984.

- Cea Egaña, José Luis. Derecho constitucional chileno. Tomo II: Derechos, deberes, garantías. Ediciones Universidad Católica de Chile. Santiago, 2003. 
- Eguiguren Praeli, Francisco. Principio de igualdad y derecho a la no discriminación. En Estudios Constitucionales, ARA Editores. Lima, 2002.

- Fernández GonzÁlez, Miguel Ángel. El principio de igualdad constitucional ante la ley. Ed. ConoSur Ltda. Santiago, 2001.

- Fiamma Olivares, Gustavo. "La igualdad. Antecedentes en las Actas de la Comisión de Estudios Constitucionales". En Revista de Derecho Público $\mathrm{N}^{\circ} 28$, Ed. Facultad de Ciencias Jurídicas y Sociales, Universidad de Chile. Santiago. 1980.

- Garay, Alberto F. La igualdad ante la ley. Ed. Abeledo-Perrot. Buenos Aires. 1989.

- García Pelayo, Manuel. Las transformaciones del Estado contemporáneo. Alianza Editorial. Madrid, 1977.

- Gómez Sánchez, Yolanda. Derechos y libertades. Ed. Sanz y Torres. Madrid, 2003.

- GonZÁlez Beilfuss, Markus. Tribunal Constitucional y reparación de la discriminación normativa. Ed. Centro de Estudios Políticos y Constitucionales. Madrid, 2000.

- González Martín, Nuria. "El principio de igualdad, la prohibición de discriminación y las acciones positivas". En Carbonell, Miguel (coordinador), Derechos fundamentales y Estado. Memoria del VII Congreso Iberoamericano de Derecho Constitucional. ED. Instituto de Investigaciones Jurídicas, Universidad Nacional Autónoma de México. México, 2002.

- Huerta Guerrero, Luis Alberto. El derecho a la igualdad, en Pensamiento Constitucional. Maestría en Derecho con mención en Derecho constitucional. Ed. Pontificia Universidad Católica del Perú. Lima. 2005.

- JimÉNEZ CAMPO, Javier. "La igualdad jurídica como límite al legislador". Revista Española de Derecho Constitucional $N^{\circ}$ 9, Ed Centro de Estudios Constitucionales. Madrid.

- Landa ARroyo, César. Tribunal Constitucional y Estado Democrático. Segunda edición. Palestra editores. Lima. 2003.

- MARTín VIDA, M.A. Fundamento y límites constitucionales de las medidas de acción positiva. Ed. Cívitas. Madrid, 2002.

- Molina Guaita, Hernán. Derecho Constitucional. LexisNexis. Santiago, 2006.

- RABOSSI, Eduardo. Derechos Humanos: "El principio de igualdad y la discriminación". Revista Centro de Estudios Constitucionales, $\mathrm{N}^{\circ} 7$, Madrid, España. 1990.

- Rosenfeld, Michel. Affirmative action and justice. Yale University Press. New Haven. 1991.

- Rubio Llorente, Francisco. "La igualdad en la jurisprudencia del Tribunal Constitucional". Revista Española de Derecho Constitucional, $N^{\circ}$ 31, Madrid, España. 1991. 
- Rubio Llorente, Francisco. Derechos Fundamentales y Principios Constitucionales. Ed. Ariel, Derecho, España. 1995.

- Ruiz-Miguel, Alfonso. "Discriminación inversa e igualdad", en El concepto de Igualdad. Ed. P. Iglesias. Madrid, 1994.

- SCHWABE, Jürgen (compilador). Cincuenta años de jurisprudencia del tribunal constitucional Federal alemán. Ed Fundación Honrad Adenauer/ Ed. Jurídicas Gustavo Ibáñez. Bogotá, 2003.

- Sosa SACIO, Juan Manuel. "El derecho-principio e igualdad en la carta de 1993, con especial referencia a la jurisprudencia del Tribunal Constitucional", en Revista Peruana de Derecho Público, año $6 \mathrm{~N}^{\circ}$ 11, julio-diciembre 2005.

- SUAY RINCÓN, José. El principio de igualdad en la justicia constitucional. ED Instituto de Estudios de Administración Local. Madrid, 1985.

- TURner, R. The past and present of affirmative action. Ed. Quórum Books. New York. 1991.

- VAldés PRIETO, Domingo. "Algunas notas sobre el principio jurídico de la igualdad". Anuario de Filosofía Jurídica y Social $N^{\circ} 9$, Sociedad Chilena de Filosofía Jurídica y Social. 1991.

- Venegas Castellanos, Alfonso. Teoría y Práctica de la acción de tutela. Editores Colombia, Ed. AVC, 1996.

- Verdugo, Mario; Pfeffer, Emilio; Nogueira, Humberto. Derecho Constitucional. Tomo I. Editorial Jurídica de Chile. Santiago, Chile, 1994.

- Villacorta MANCebo, Luis. "Principio de igualdad y legislador: arbitrariedad y proporcionalidad como límites", en Revista de Estudios Políticos $N^{\circ} 130$, octubre-diciembre 2005, Centro de Estudios Políticos y Constitucionales, Madrid. 2005.

- Xynopoulos, G. Le controle de proportionnalité das le contentieux de la constitutionnalité et de legalité en France, Allemagne et Angleterre. Ed. LGDJ. Paris, 1995.

- ZÚNiga Urbina, Francisco. "Derechos humanos e Igualdad: del principio de discriminación compensatoria", en XXV Jornadas de Derecho Público, Ed. Edeval. Valparaíso, 1994. 